\title{
Pirámide de las Pinturas de San Bartolo, El Petén, Guatemala: espacialidad
}

\section{The Pyramid of the Paintings at San Bartolo, El Peten, Guatemala: Spatiality}

\author{
SAnJa SAVKIC \\ Programa de Becas Postdoctorales, \\ Instituto de Investigaciones Antropológicas, UNAM
}

\begin{abstract}
Resumen: El objetivo del presente trabajo es tratar de entender los posibles usos y significaciones de los espacios construidos —arquitectónicos y pictóricos- del grupo las Pinturas de San Bartolo, El Petén, Guatemala (ante todo su tercera y sexta fases arquitectónicas), según la información de diversa índole obtenida hasta el año 2014. Se trata de los espacios configurados intencionalmente de una manera determinada —intelectual y sensiblemente- para significar algo. La misma configuración visual revela qué es y para qué es. En las culturas dominadas por las creencias religiosas, como la maya antigua, se trata de los espacios materiales, reales, manifestados e imbuidos de un componente espiritual; por ello, abundan los signos iconográficos y escritos que los designan.
\end{abstract}

Palabras clave: San Bartolo, Pirámide de las Pinturas, espacialidad, mayas del Preclásico, Petén guatemalteco.

ABSTRACT: The objective of this paper is try to understand the possible uses and meanings of the built environment — architectural and pictorial spaces - of Las Pinturas Group at San Bartolo, El Peten, Guatemala (particularly its third and sixth arquitectural phases), according to diverse type of information obtained until 2014. It is about the space configured in a certain way —intellectually and sensitively — to mean something. The visual configuration itself reveals what it is and for what it is. In cultures dominated by religious beliefs, as the ancient Maya, they are material, real spaces, manifested and imbued with a spiritual component; therefore, there are many iconographic and written signs that designate them.

Kerwords: San Bartolo, The Pyramid of the Paintings, spatiality, Preclassic Maya, Guatemalan Peten.

RECEPCIÓN: 4 de mayo de 2016.

ACEPTACIón: 19 de agosto de 2016.

DOI: 10.19130/iifl.ecm.2017.50.805.

Las excavaciones arqueológicas realizadas a partir de mediados de los años setenta del siglo pasado cambiaron de manera significativa nuestras ideas sobre el período Preclásico en las Tierras Bajas centrales mayas. Los datos recolectados tras años de investigación en varios sitios —Cerros, Cuello, Tikal, Uaxactún, El Mirador, 
Cival entre otros - han mostrado las características sumamente establecidas, de las cuales destacan la planeación urbanística, la arquitectura monumental, la organización social compleja y, con ello, la especialización de los oficios, el panteón de las deidades, la sofisticación de los rituales y del arte así como el inicio de la escritura. Una de las dificultades para poder corroborar que diferentes manifestaciones de ese período ni eran más sencillas ni apenas en formación fue el hecho de encontrar los materiales que, por lo general, estaban enterrados debajo de diferentes estructuras y/o se encontraban en lugares poco accesibles debido a su geografía, como es el caso con el sitio arqueológico San Bartolo, ${ }^{1}$ con la mayor ocupación en el período Preclásico Tardío (400 a.C.-100 d.C.). ${ }^{2}$

Con esos datos se confirma que la civilización maya en las Tierras Bajas (Mapa 1) tuvo un desarrollo mucho más temprano de lo que anteriormente se pensaba, pues se consideraba que el inicio de la civilización maya se remontaba hacia el año 300 d.C., mucho después de otros pueblos de Mesoamérica, lo cual implicaba que sus orígenes venían de afuera de esa área. Igualmente, en San Bartolo resalta la presencia de los textos jeroglíficos fechados cerca del año 300 a.C. Se sabe que alrededor de 400 a.C. los sistemas escriturarios se establecieron en Oaxaca y posiblemente en el Istmo de Tehuantepec; sin embargo, con el descubrimiento de los textos de San Bartolo, ahora se considera que los mayas también formaron parte de las culturas que usaban la escritura mucho antes de lo que previamente se creía.

San Bartolo se hizo famoso desde el mes de marzo de 2001, cuando William Saturno descubrió, inesperadamente, un muro pintado mientras desarrollaba el proyecto de "Corpus de Inscripciones Jeroglíficas Mayas". ${ }^{3}$ Este arqueólogo entró

${ }^{1}$ San Bartolo se encuentra en la cuenca del río Ixcan, en la zona noreste del Departamento de El Petén, Guatemala. Está aproximadamente a $42 \mathrm{~km}$ al norte de Uaxactún, el poblado más cercano, y a 8 km de Xultún. Ocupa un área delimitada por el Instituto Nacional de Antropología e Historia de Guatemala de aproximadamente $4 \mathrm{~km}^{2}$; su área central se extiende en cerca de $1 \mathrm{~km}^{2}$, rodeada por bajos por todos sus lados. Se han encontrado aguadas artificiales que proveían a la ciudad de ese líquido.

${ }^{2}$ El presente trabajó toma como base algunas ideas de mi tesis de doctorado (véase Savkic, 2012) y es producto de mi participación en la reunión académica Ciclo de conferencias de arqueología "Investigaciones recientes en el Petén guatemalteco", que se llevó a cabo en diciembre de 2014 en el Centro de Estudios Mayas, Instituto de Investigaciones Filológicas, Universidad Nacional Autónoma de México.

${ }^{3}$ Desde el año 2002 hasta la fecha en San Bartolo se han realizado temporadas de investigaciones de campo (en 2010 y 2013 no hubo excavaciones), que incluyen actividades de diferente tipo: estudios del patrón de asentamiento local, la extensión y la cronología del sitio, la colindancia con otras entidades, la red de intercambio por medio de los materiales recuperados, los medios de subsistencia, el manejo de los recursos, la botánica, así como estudios de arquitectura monumental y residencial, arte, escritura y la importancia del sitio en las Tierras Bajas mayas, los que han permitido reconocer su indudable valor en la historia de esa civilización.

Los trabajos profesionales efectuados en el sitio de San Bartolo se han llevado a cabo de manera consecutiva desde el año 2002 (siempre bajo la dirección de William Saturno), mientras que las investigaciones en Xultún se iniciaron en el año 2008. En la novena temporada de campo realizada en el año 2010 las investigaciones se enfocaron principalmente en el sitio Xultún, por lo que el Proyecto Arqueológico Regional San Bartolo cambió de nombre al Proyecto Arqueológico Regional San BartoloXultún a partir de ese año. 


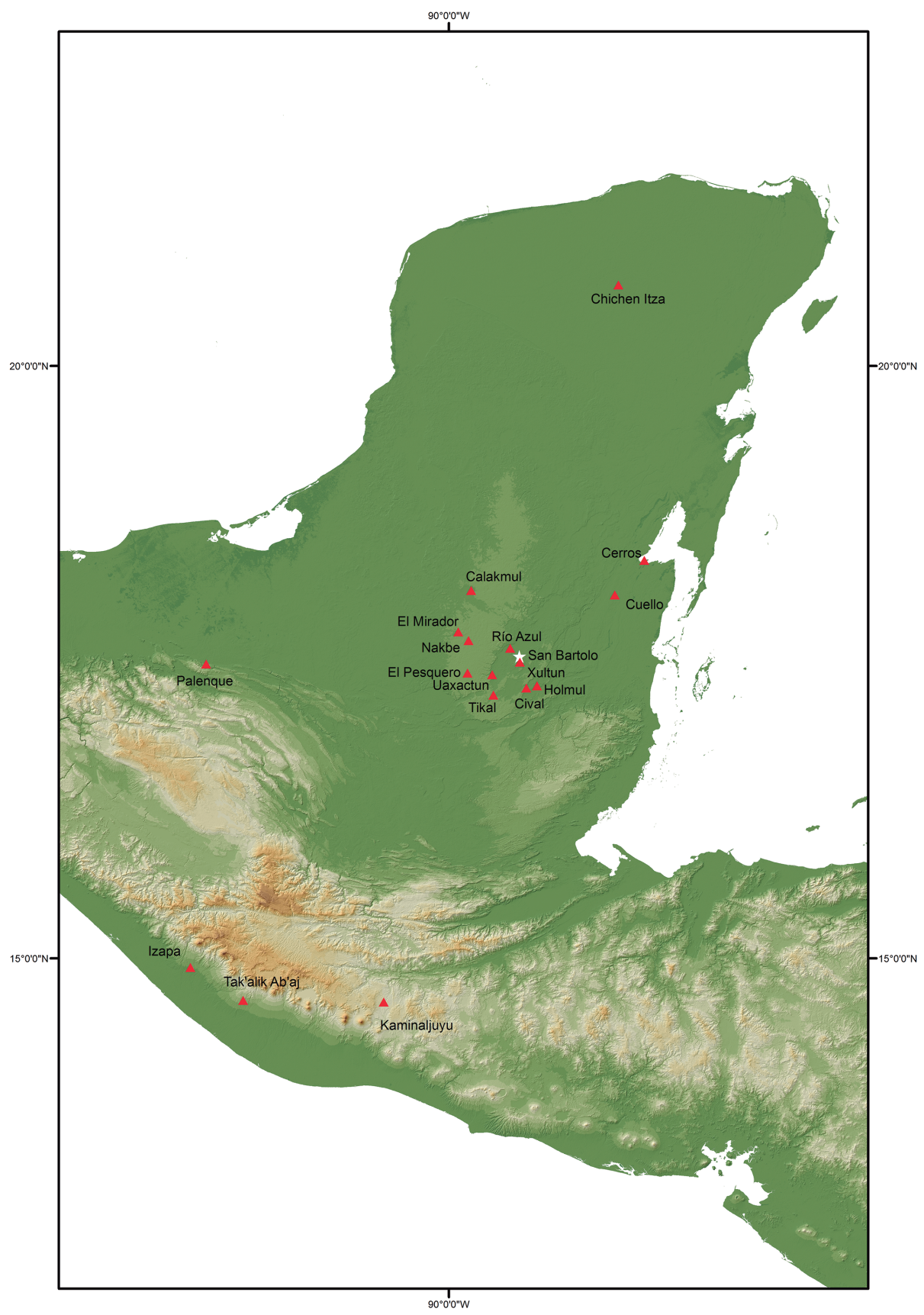

Mapa 1. Área maya; se resalta una parte de las Tierras Bajas centrales.

Realizado por Gerardo Jiménez Delgado (Mapoteca del Instituto de Investigaciones Antropológicas, Universidad Nacional Autónoma de México). 
en un túnel hecho por los saqueadores, en el cual se encontraba expuesto un mural en buen estado de conservación.

El análisis de los artefactos cerámicos (Rivera, 2009) demostró que el sitio estuvo ocupado desde el Preclásico Medio hasta el Clásico Tardío. Los resultados de los análisis también revelaron que los artesanos de San Bartolo interactuaron con otras ciudades y regiones. Con base en los datos obtenidos, se puede sostener que el período de mayor crecimiento social y cultural de ese sitio sucedió durante el Preclásico Tardío. ${ }^{4}$

Desde sus inicios, este Proyecto se ha enfocado principalmente al salvamento y a la conservación de los murales de la Pirámide de las Pinturas en el sitio San Bartolo, sin dejar de lado otras actividades: las excavaciones sistemáticas y los sondeos exploratorios, asimismo el refinamiento de las etapas cronológicas del sitio, por medio del análisis tipológico de la cerámica y otros artefactos arqueológicos recuperados mediante diferentes trabajos de investigación emprendidos por diversos equipos científicos. En el año 2002 el sitio de San Bartolo fue recorrido con la finalidad de elaborar un mapa preliminar; además, se siguió trabajando en la cámara en la cual un año antes se localizó una pintura mural en la pared del lado norte, la misma que hizo conocido ese sitio y la que dio el nombre al grupo arquitectónico completo y a su edificio principal (el Grupo de las Pinturas y la Pirámide de las Pinturas, respectivamente). Al año siguiente (2003) continuaron los trabajos de investigación y conservación; quizás lo más distintivo fue el encuentro de una cornisa de estuco con pintura roja en el exterior de la Sub-1A, en la fachada del lado norte. Para 2004 el hallazgo principal fue el descubrimiento del Mural Oeste. En la excavación del año 2005 se continuó con la liberación de los murales y fue descubierto un nuevo edificio hacia el norte del ya conocido, denominándolos, ahora, Sub-1A (edificio de los murales) y Sub-1B (el recién descubierto). También fueron iniciadas las investigaciones de los estadios constructivos de la Pirámide de las Pinturas, lo que posibilitó una definición preliminar de las primeras tres etapas constructivas, nombradas Ixquic, Ixmucane e Ixbalamque (primera, segunda y tercera etapa constructiva, respectivamente, o Sub-8, Sub-7 y Sub-6). En la temporada de trabajo del año 2006 se logró determinar un total de ocho etapas constructivas. Los trabajos fueron enfocados específicamente a Ixbalamque e Ixim, cuando se exhibieron otras evidencias de las pinturas murales, así como la presencia de nuevos rasgos arquitectónicos. Con los resultados que se han obtenido hasta 2012 se confirma que las primeras tres ocupaciones del complejo arquitectónico de las Pinturas Sub-8, 7 y 6 se asocian con la arquitectura tipo grupo E, fechadas para el período Preclásico (finales del Medio e inicios del Tardío). En la primera etapa constructiva o Pinturas Sub-8 se identificaron restos de un piso estucado, asimismo la presencia de dos lajas y varios bloques de caliza labrados que podrían pertenecer a los cimientos de un muro. En la segunda etapa de ocupación, Pinturas Sub-7, se presentó un piso estucado en buen estado de conservación. Para una mayor información sobre el trabajo de campo y gabinete véase los Informes de trabajo del Proyecto Arqueológico Regional San Bartolo-Xultún.

${ }^{4}$ A partir de la muestra de cerámica Pre-Mamom se pudo aseverar que alrededor del año 900 a.C. en San Bartolo ya existía una actividad humana organizada; no obstante, todavía no se puede asegurar nada sobre el origen de los pobladores del lugar, puesto que no se sabe si sólo se trata de un intercambio de esa cerámica temprana entre los habitantes de las áreas central y oriental de las Tierras Bajas mayas o si, quizás, los aldeanos que ocuparon San Bartolo ya la conocían y la traían consigo en la búsqueda de la tierra fértil. Lo que sí se sabe con bastante seguridad es que entre los años 600 y 300 a.C. existía el intercambio de la cerámica con otras regiones, además del desarrollo de las actividades propias de producción, las cuales se reforzaron en el Preclásico Tardío. En los inicios del complejo Ixbalamque (Preclásico Tardío) se observan avances en la producción cerámica, así como en su interacción, destacando la afinidad en tipos y modos tanto con la región de Belice como con el centro de El Petén (Tikal y Uaxactún, por ejemplo), siendo, al parecer, más estrechos los vínculos con la región beliceña. En el período Clásico Temprano (complejo Jabalí) hubo una disminución demográfica considerable; supuestamente, la gran parte de la población emigró a sitios cercanos como Xultún. Durante el complejo Mono del Clásico Tardío la población volvió a crecer, aunque sin alcanzar el nivel de desarrollo que tuvo durante el período Preclásico; la mayor parte de la cerámica de este complejo procede de distintos grupos residenciales. 


\section{Grupo las Pinturas}

El conjunto arquitectónico las Pinturas de San Bartolo (Plano 1) es llamado así por el hallazgo de las pinturas murales - las cuales dieron fama mundial a este sitio- que se encuentran en la sexta (de ocho en total [Figura 1]) etapa constructiva (ahora llamada antepenúltima) ${ }^{5}$ de su estructura central, denominada Pirámide de las Pinturas o Estructura 1, con orientación al oeste. Aún más sorprendente fue el descubrimiento de la evidencia pictórica y escrituraria, como parte de los acabados de las estructuras, desde el tercer estadio constructivo, lo cual indica una tradición iniciada antes del año 300 a.C.

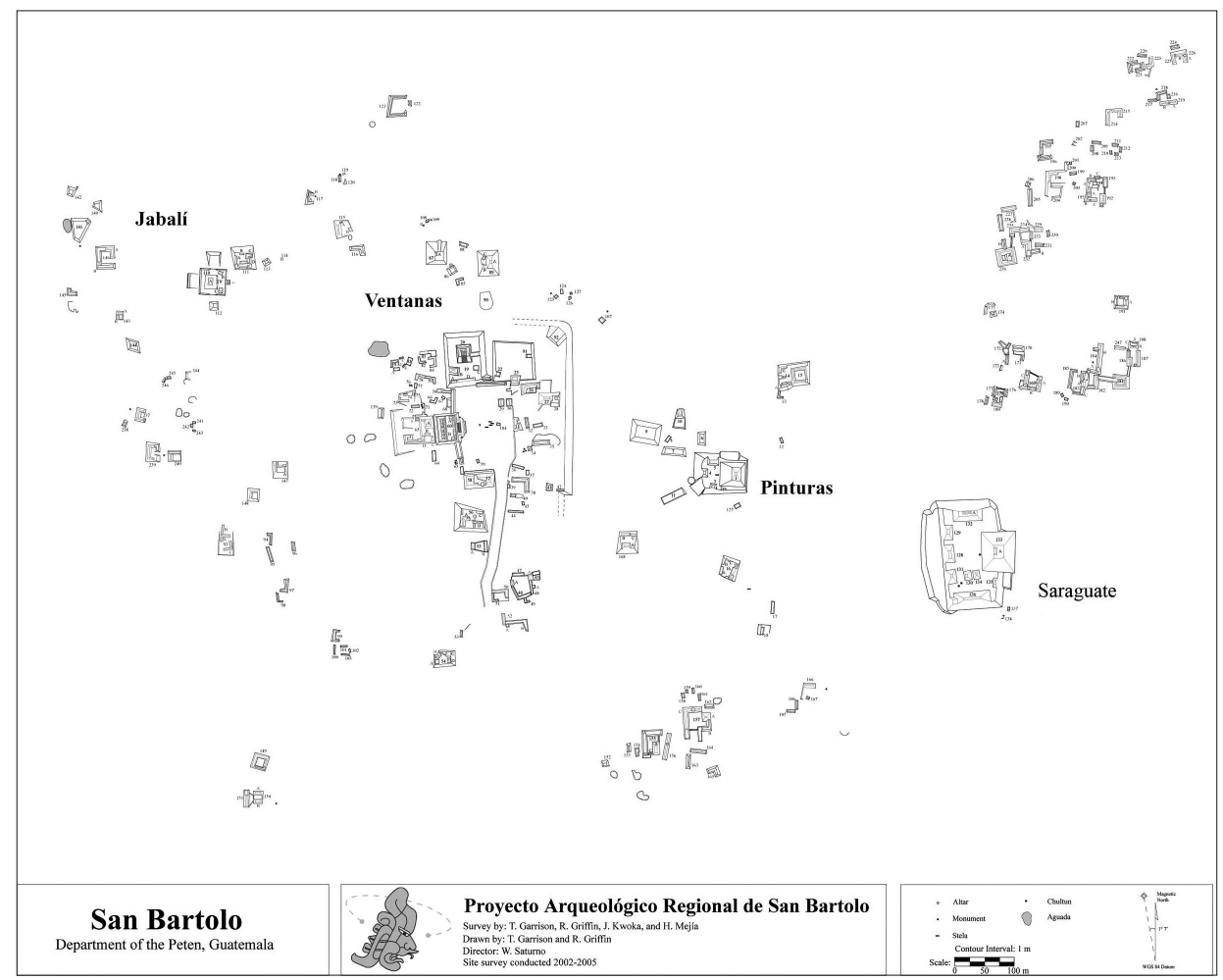

Plano 1. Sitio arqueológico San Bartolo, El Petén, Guatemala.Dibujo de T. Garrison y R. Griffin (según el trabajo de inspección realizado entre 2002 y 2005 por T. Garrison, R. Griffin, J. Kwoka y H. Mejía); Proyecto Regional Regional San Bartolo-Xultún, dirigido por W. Saturno.

${ }^{5}$ Debido al descubrimiento de la última versión de las Pinturas en el año 2006 la nomenclatura cambió: antes de la quinta temporada de excavación se creía que la estructura Ixim, plataforma Yaxché y las subestructuras 1A y 1B conformaban la penúltima etapa constructiva, pero precisamente por el hallazgo de la última etapa, el conjunto de estas cuatro estructuras fueron renombradas como antepenúltima etapa, mientras que lo que anteriormente llevaba por nombre última etapa, ahora se denomina penúltima etapa constructiva. 


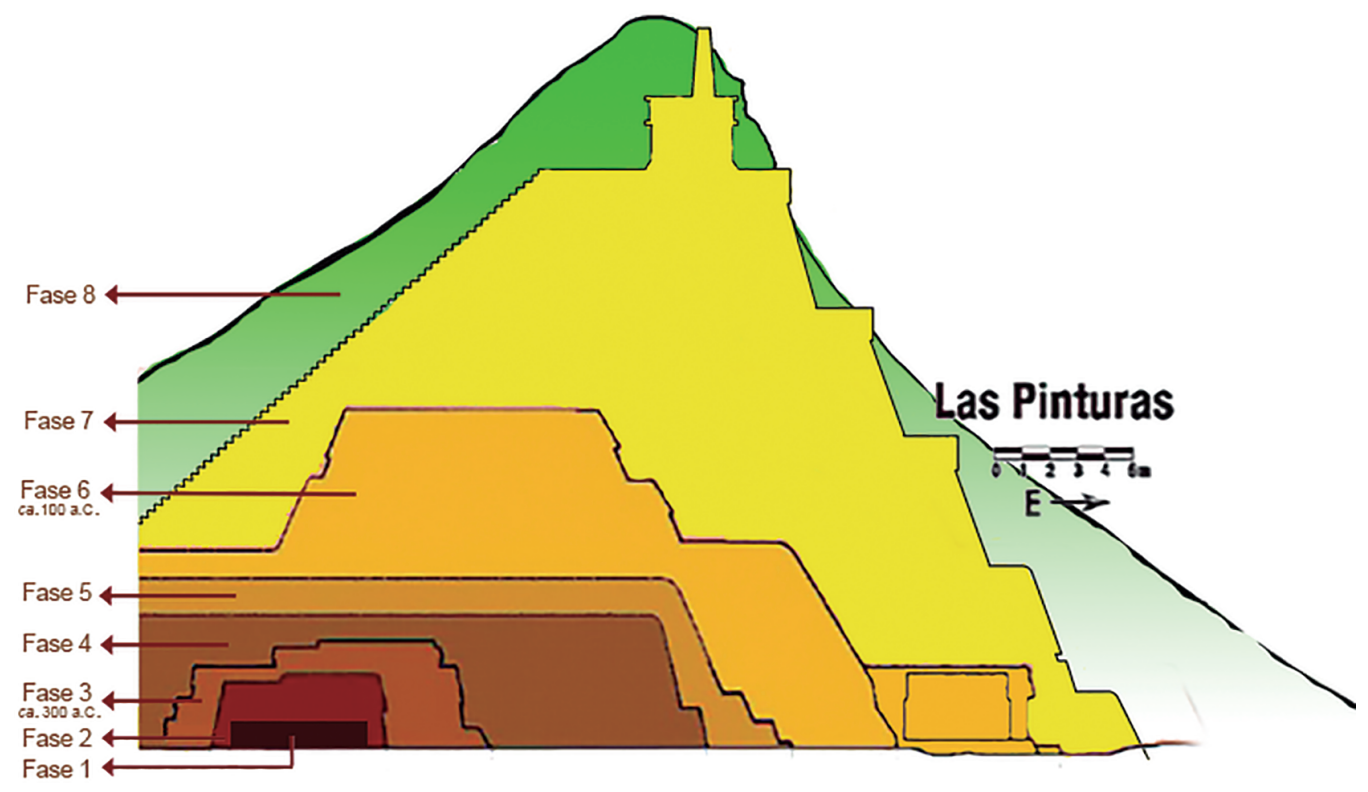

Figura 1. Corte vertical mostrando las fases arquitectónicas de la Pirámide de las Pinturas de San Bartolo, El Petén, Guatemala. Imagen modificada por Massimo Stefani, según la figura 3, página 1282, en William A. Saturno, David Stuart y Boris Beltrán (2006).

Este grupo se encuentra en medio de otros dos: al noroeste, a unos $500 \mathrm{~m}$, está el conjunto las Ventanas (el más grande del sitio), mientras que al sureste se encuentra el Saraguate, aproximadamente a la misma distancia. Hay que mencionar también al pequeño grupo Jabalí, el cual se ubica hacia el noroeste de las Ventanas, y está constituido por un complejo arquitectónico de patrón triádico, lo que indica sus connotaciones rituales. En una de las ocupaciones se han hallado ofrendas en tres pisos cortados y una tumba con una suntuosa ofrenda, fechada para el Preclásico Medio.

El conjunto arquitectónico las Pinturas está compuesto por cuatro estructuras asentadas en los cuatro puntos cardinales (Figuras 2a-c), que se elevan sobre una plataforma rectangular de sustentación de $c a .75 \mathrm{~m}$, en dirección norte-sur y ca. $90 \mathrm{~m}$ este-oeste, aprovechando un declive natural al este, formando, de este modo, una plaza cerrada. La estructura ubicada al este de esa plaza es la Estructura 1 o Pirámide de las Pinturas; corresponde a una estructura en forma de pirámide escalonada orientada hacia el oeste, siendo la más alta de todas ellas, con 27 m de altura aproximadamente; lo que se observa en la actualidad es la séptima fase con los restos de la octava, inconclusa; al fondo de la escalinata central se localiza la Estela 5. 


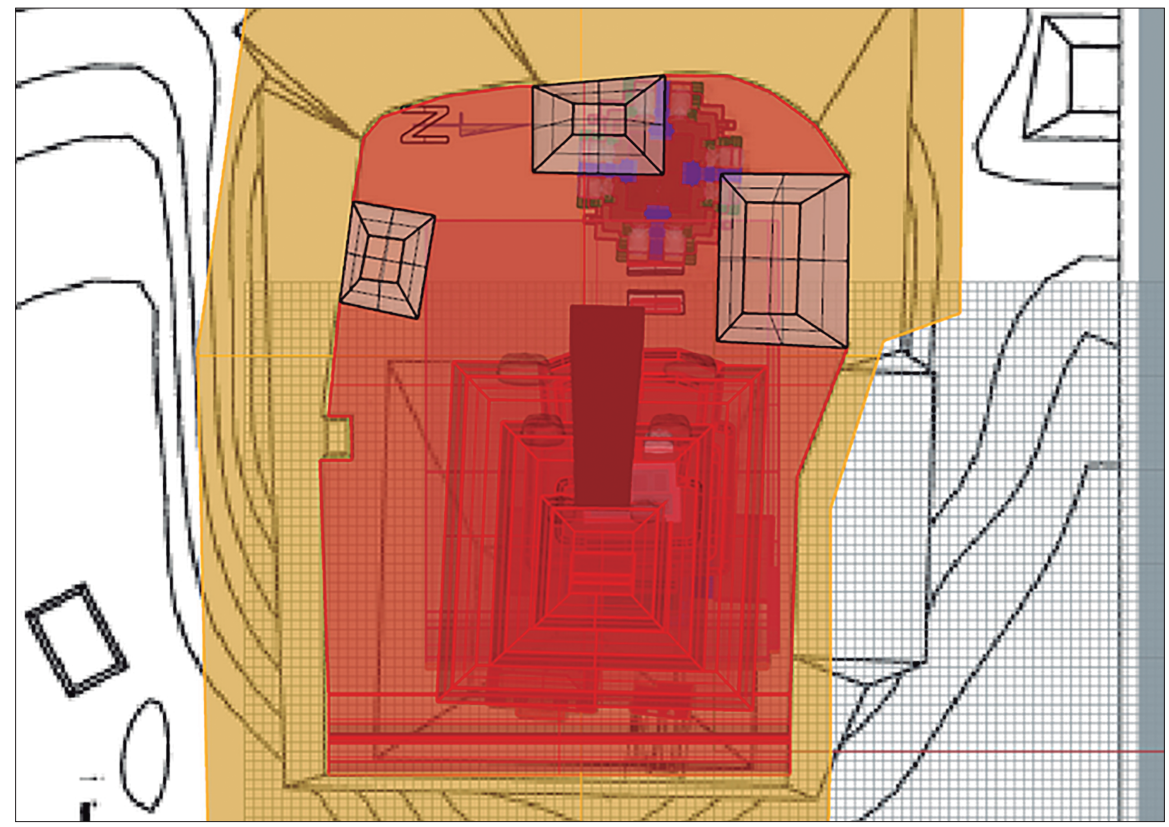

a

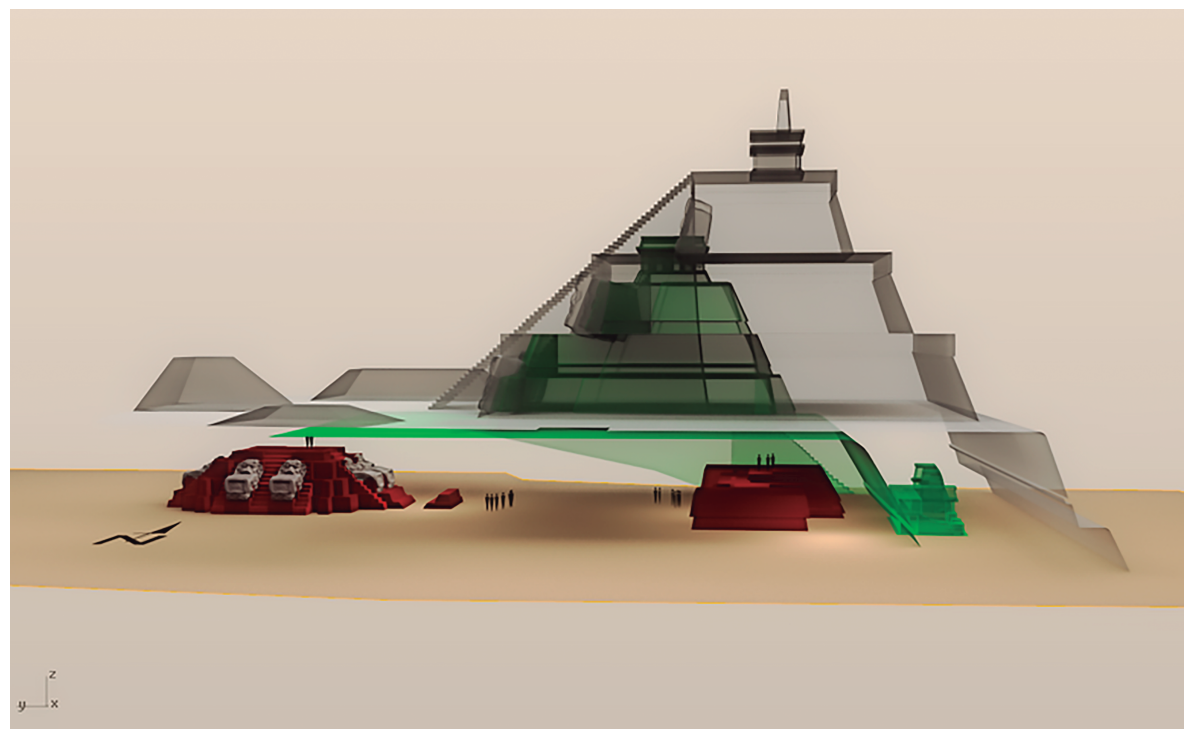

b

SAVkic / PIRÁmide de las pinturas de SAN Bartolo, el petén, guatemala 




C

Figuras 2a-c. Grupo las Pinturas de San Bartolo, El Petén, Guatemala. Se resaltan la tercera, la sexta y la séptima fases arquitectónicas.

Imágenes digitales en tres dimensiones realizadas por Massimo Stefani.

Por desgracia, en el pasado este complejo arquitectónico fue excavado varias veces de manera ilícita. En la actualidad cuenta con túneles de investigación, los cuales forman parte de la exploración arqueológica; siete estadios constructivos fueron erigidos antes de la etapa final, la cual, posiblemente, nunca fue terminada. El primero pertenece a finales del período Preclásico Medio y la última fase se estableció para el final del Preclásico Tardío (ca. 500/400 a.C.-100 d.C.). ${ }^{6}$ Hasta la fecha poco se sabe de la cuarta y la quinta fases constructivas.

\section{La tercera fase arquitectónica de la Pirámide de las Pinturas}

Según Beltrán y Saravia (2012), Pinturas Sub-6 es un pequeño grupo compuesto por tres estructuras (Figuras 3a-b). La primera se llama Pinturas Sub-6A o Ixbalamque; es una plataforma rectangular ${ }^{7}$ con banquetas laterales, ${ }^{8}$ la que en la parte superior sustentó una estructura, de la cual sólo se conoce un cuerpo ${ }^{9}$ y

${ }^{6}$ El fechamiento se obtuvo por medio de una combinación de la datación estilística cruzada, los materiales cerámicos, así como mediante la datación por radiocarbono.

${ }^{7}$ De $26 \mathrm{~m}$ (norte-sur) por $12.46 \mathrm{~m}$ (este-oeste) y $2.18 \mathrm{~m}$ de alto.

${ }^{8}$ De $0.50 \mathrm{~m}$ en dirección norte-sur.

${ }^{9}$ De $0.70 \mathrm{~m}$. 
el basamento complementario ${ }^{10}$ donde se identificó la huella de un muro y una jamba, lo que indica que la fachada frontal se orientó hacia el oeste; de aquí se conocen unas pinturas fragmentarias y un texto jeroglífico (Figura 4). La edificación incluye cuatro cuerpos con las características de muro con moldura y talud y cinco escalinatas remetidas: dos laterales anteriores en la fachada este, dos laterales posteriores y una central en la fachada oeste.

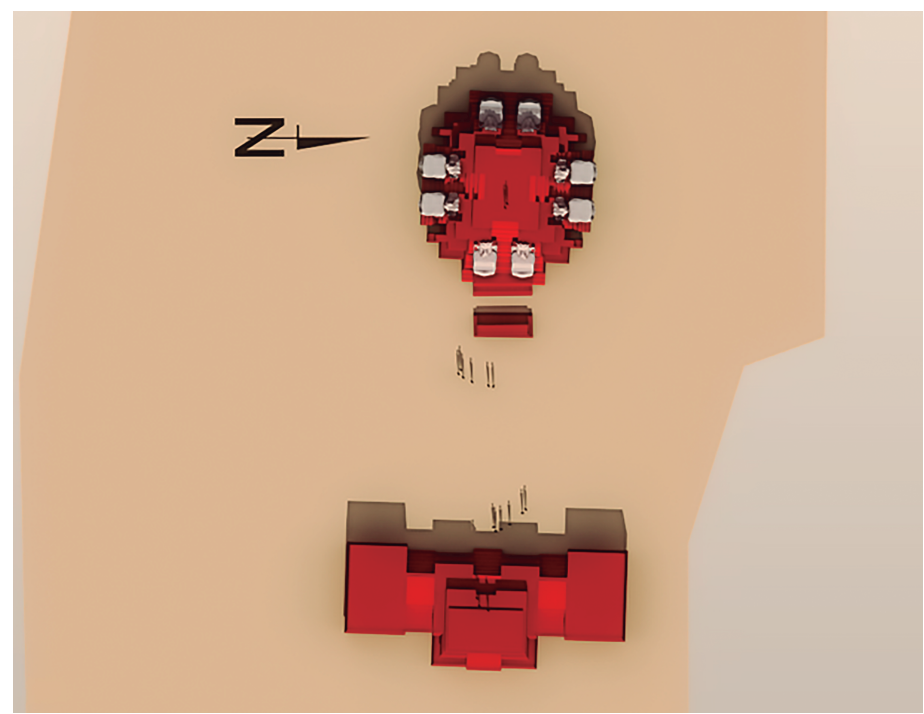

a

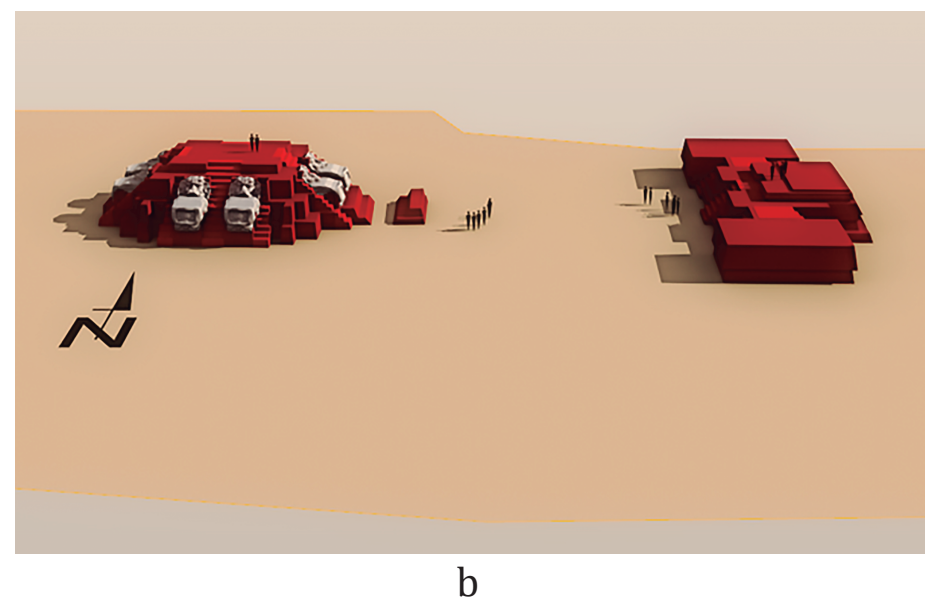

Figuras 3a-b. La tercera fase arquitectónica de la Pirámide de las Pinturas de San Bartolo, El Petén, Guatemala (ca. 300 a.C.).

Imágenes digitales en tres dimensiones hechas por Massimo Stefani.

${ }^{10}$ De $0.26 \mathrm{~m}$. 


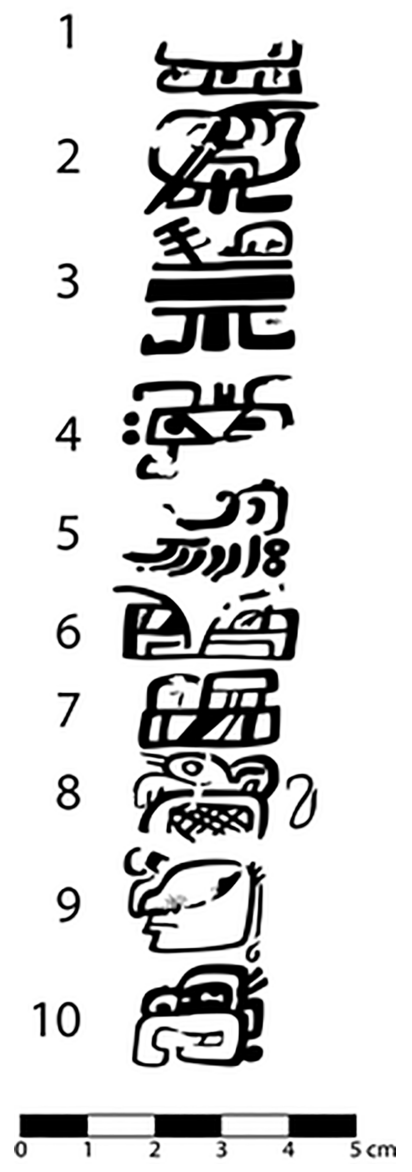

Figura 4. El texto jeroglífico de la tercera fase arquitectónica de la Pirámide de las Pinturas de San Bartolo, El Petén, Guatemala (ca. 300 a.C.). Dibujo de Felix Kupprat.

Es importante notar que ya en el Preclásico Medio/Tardío la escritura formaba parte integral del recubrimiento parcial de las fachadas arquitectónicas y de las pinturas murales mayas. Los textos cortos de San Bartolo demuestran que desde ese período los mayas utilizaban el texo y la imagen como dos formas complementarias para transmitir información sobre diversos hechos y que ambas fueron completamente desarrolladas desde esa época temprana. ${ }^{11}$

${ }^{11}$ Los textos jeroglíficos en San Bartolo se pintaron en columnas (tanto con sílabas como con logogramas o, por lo menos, logosílabas); aunque no abundan, su presencia es importante, puesto que demuestran la utilización de la escritura desde las fechas más tempranas de lo que se solía pensar antes de su hallazgo. No sólo que se localizan en el interior de la Sub-1A e Ixim y en el exterior de la Sub-1B (ca. 100 a.C.), sino también en Ixbalamque, que por la fecha aproximada tiene el siglo IV 
A $18.1 \mathrm{~m}$ al oeste de Ixbalamque se localiza un juego de pelota de pequeñas dimensiones, identificado como Pinturas Sub-6C. Se compone de dos plataformas con orientación norte-sur. ${ }^{12}$ Del lado oeste el patio del juego de pelota ${ }^{13}$ está abierto en los extremos norte y sur; en el centro de la cancha se localiza un marcador pintado de color rojo ${ }^{14}$ (Figura 5). La plataforma oeste, ${ }^{15}$ a diferencia de la plataforma este, no presenta banquetas laterales y se encuentra adosada a la fachada este de la estructura Pinturas Sub-6B o Hunahpú.

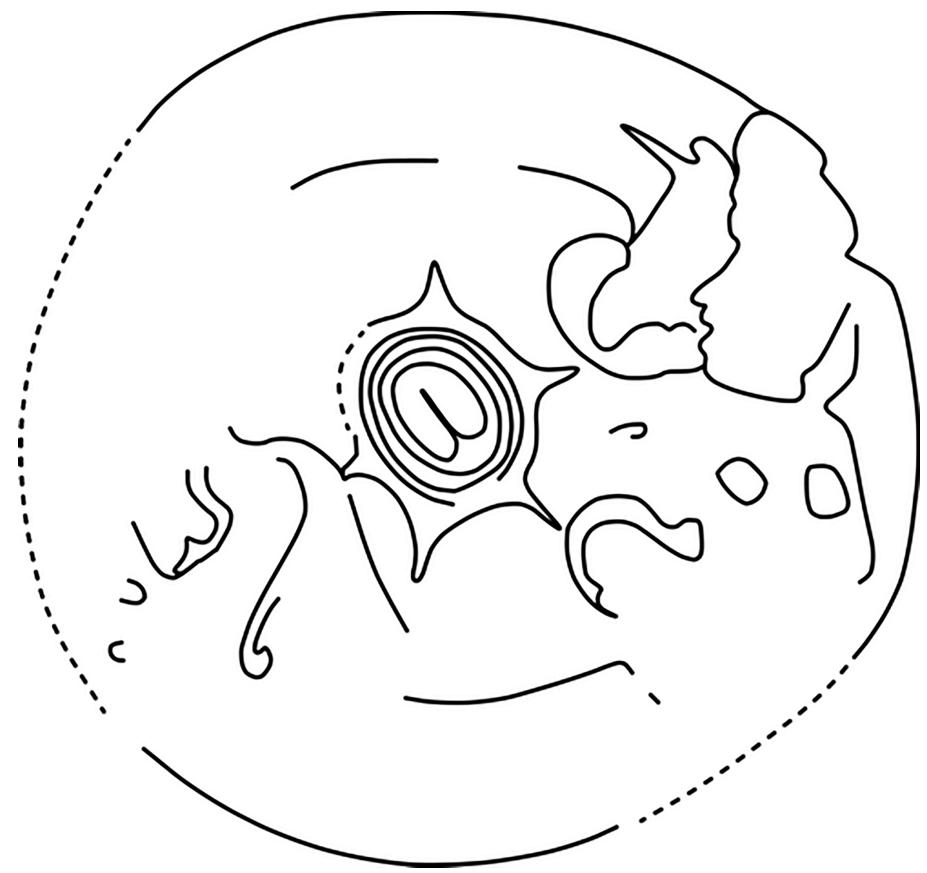

Figura 5. Marcador del juego de pelota de la tercera fase arquitectónica de la Pirámide de las Pinturas de San Bartolo, El Petén, Guatemala (ca. 300 a.C.). Dibujo de Felix Kupprat.

La estructura Hunahpú es una pirámide radial; ${ }^{16}$ presenta tres cuerpos escalonados con dos escalinatas auxiliares y una central. Posee relieves en estuco modelado en el segundo y el tercer cuerpo; el primero de ellos sustenta dos parapetos con la figura que fue identificada como serpiente con plumas con las fauces

a.C., y que es la evidencia escrituraria más temprana que se ha reportado hasta ahora en las Tierras Bajas mayas.

${ }^{12}$ De $6 \mathrm{~m}$ (norte-sur) por $2.58 \mathrm{~m}$ (este-oeste) y $1.22 \mathrm{~m}$ de alto.

${ }^{13}$ De $1.70 \mathrm{~m}$ de ancho.

${ }^{14}$ De $0.45 \mathrm{~m}$ de diámetro.

${ }^{15}$ Mide $6 \mathrm{~m}$ (norte-sur) por $2.12 \mathrm{~m}$ (este-oeste) y $1.18 \mathrm{~m}$ de alto.

${ }^{16}$ De 15.36 m (norte-sur) y $4.58 \mathrm{~m}$ de alto. 
abiertas, mientras que el segundo tiene dos mascarones en forma de la cabeza de jaguar; ${ }^{17}$ ambas esculturas son flanqueadas por las escalinatas central y lateral.

Uno de los rasgos identificados en la parte superior de Hunahpú es un agujero, posiblemente de un poste, ubicado en la plataforma saliente donde se encuentra adosado el mascarón norte de la fachada este, lo que permite inferir que la estructura no contó con un edificio de mampostería en la parte superior, sino que la presencia de huellas de un poste indica que tuvo uno de material perecedero.

Esta fase arquitectónica de la Pirámide de las Pinturas de San Bartolo cabe dentro de los complejos denominados Grupo del Tipo E, los cuales, según las palabras de Atasta Flores Esquivel:

consisten básicamente en un arreglo de plaza cuyo lado poniente lo ocupa una estructura piramidal de planta cuadrangular y su lado oriente una plataforma rectangular alargada, con uno o tres edificios alineados en su parte superior. [...] Actualmente se reconoce como una de las configuraciones de arquitectura pública más antiguas en el área maya y como un elemento "focal" en el desarrollo de muchos sitios como centros urbanos (2000: 111).

Un rasgo distintivo de este arreglo arquitectónico es la cancha para el juego de pelota adosada a la pirámide radial. Hasta la fecha se conocen algunos ejemplos de juegos de pelota posicionados entre la pirámide radial y la plataforma rectangular alargada, por lo que la disposición de las estructuras de la tercera fase arquitectónica de Las Pinturas de San Bartolo en este sentido es única.

Los Complejos del Tipo E existieron desde el Preclásico Medio y sus posibles funciones se han interpretado de varias maneras: ha persistido la hipótesis astronómica en su variante equinoccial-solsticial, su asociación con aspectos del calendario y los ciclos agrícolas, su posible función como marcadores del cuarto del año, su vínculo con ritos de conmemoración de katunes y su escenificación "teatral". También se ha sugerido que pudieran asociarse con una representación simbólica de mitos concretos, como el de la casa del "Primer Padre", Wak Chan, y las tres piedras del fogón de la creación (Flores, 2000: 113). Es interesante observar que la mayoría de estas interpretaciones se relacionan con los ciclos temporales.

Flores Esquivel hace notar que se ha señalado la diferencia del carácter "público" de las plazas que contienen Grupos del Tipo E respecto al carácter de "élite", las cuales principalmente se configuran por templos-pirámide y Acrópolis con tumbas de ancestros reales. Sobre las posibles significaciones y funciones de este tipo de complejos arquitectónicos este autor concluye lo siguiente:

Si esta suposición se acerca a la verdad en sus aspectos generales, entonces los alineamientos que se presentan se revelan como bastante significativos, pues qui-

\footnotetext{
${ }^{17}$ Hay que notar las similitudes iconográficas y de posicionamiento entre estos mascarones y los de la Estructura E-VII-Sub de Uaxactún.
} 
zás expresan en algún sentido una unión o lazo que proporcionaba cohesión a la sociedad. Si los distintos planos de plaza, definidos por sus constituyentes arquitectónicos, escultóricos, simbólicos y espaciales expresan diferencias de culto específicas, y por ende religiosas, entonces se revela como importante notar las diferencias entre los planos de ellas y como fundamental el análisis sistemático de sus constituyentes y sus posibles funciones. Si se limita a comentar que las plazas funcionaban como "teatros" para representaciones rituales, sin entrar en la identificación e interpretación concreta de sus formas, quizás no se pueda definir mayores referentes para la investigación (Flores, 2000: 117).

Regresando al grupo las Pinturas de San Bartolo, es importante observar que después de la tercera fase arquitectónica se edificaron dos más antes de llegar a la sexta, meollo de este ensayo. Lamentablemente, todavía no se conocen las características de la cuarta y la quinta fases con mayor detalle, por lo que no es posible saber si el arreglo del Grupo Tipo E persistió en el tiempo o hubo cambios en la disposición de las estructuras, tal como se observa en la sexta fase, tema del siguiente apartado.

\section{La sexta fase arquitectónica de la Pirámide de las Pinturas}

Esta fase del grupo las Pinturas es fechada aproximadamente para el año 100 a.C. Se observa que esta versión de la Pirámide de las Pinturas es un conjunto arquitectónico bastante complejo (Figuras 6a-c); consta de cuatro estructuras que son la plataforma Yaxché de un solo cuerpo en forma de delantal, edificio Ixim encima de ella y colocado de modo adicional sobre un basamento de tres cuerpos escalonados (destacando así la verticalidad), asimismo los edificios denominados Sub-1A y Sub-1B. Su disposición forma dos espacios o dos plazas separadas por la plataforma Yaxché: una arriba de ella marcada por Ixim (con orientación al oeste) y la otra, detrás de ella y a nivel del terreno (que da al este tomando en consideración la estructura más grande), conformada por las subestructuras 1A y 1B (lo que enfatiza la horizontalidad, que se subraya por la presencia de techos planos).

De ese modo, la plataforma Yaxché a la vez es el elemento que disgrega Ixim de otros dos edificios y también el que los une; la unión se articula de tal manera que la parte posterior — del lado oeste — de la Sub-1A está adosada a la plataforma y también mediante una escalera en la esquina noreste de la misma, que permitía el paso entre estas dos plazas. Desde esta perspectiva, una plaza se puede entender como elevada y otra como baja, ${ }^{18}$ tomando como referente la plataforma. Esa particular disposición de las estructuras en el entorno construido indica la manera

18 Que podría tener alguna relación con las plazas de tipo hundido. Es importante mencionar que la presencia y la importancia de las plazas hundidas existió desde el Preclásico Medio en varios lugares de Mesoamérica que, por lo general, se relacionan con el agua y diferentes objetos en forma cuadrifoliar o su variante pacial, trifoliar. 


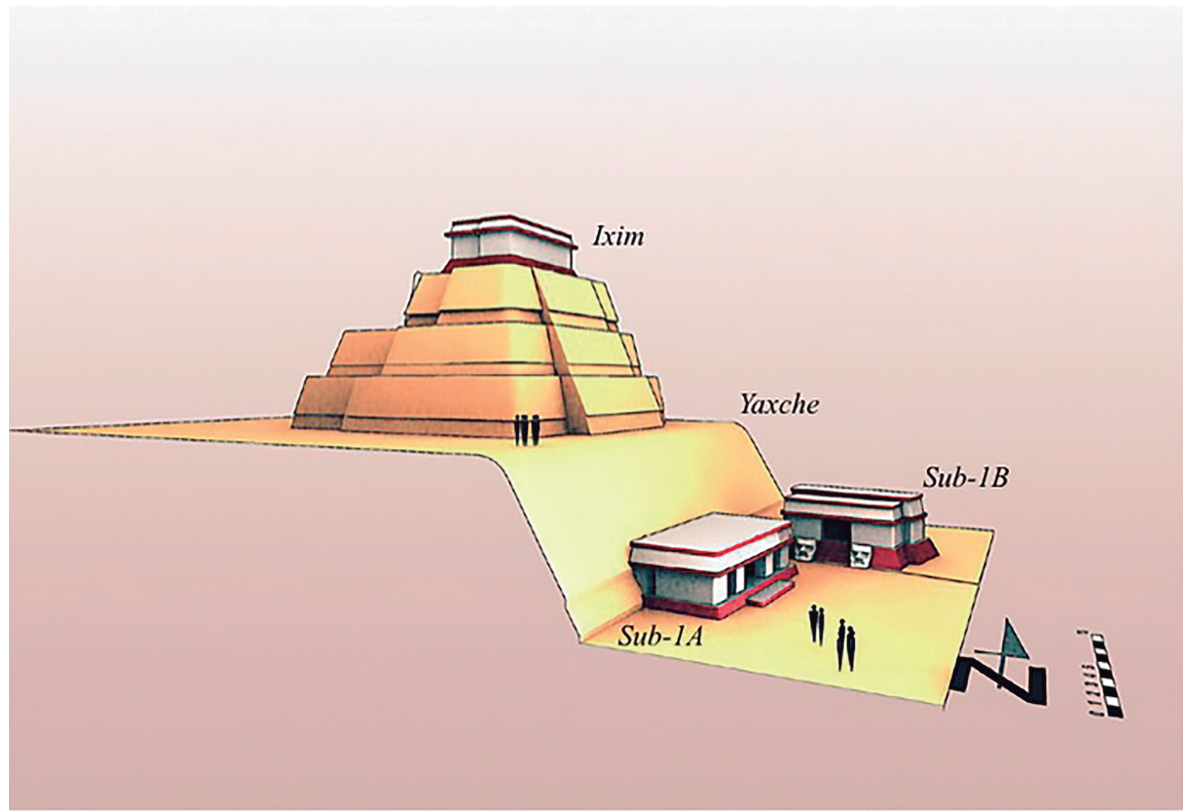

a






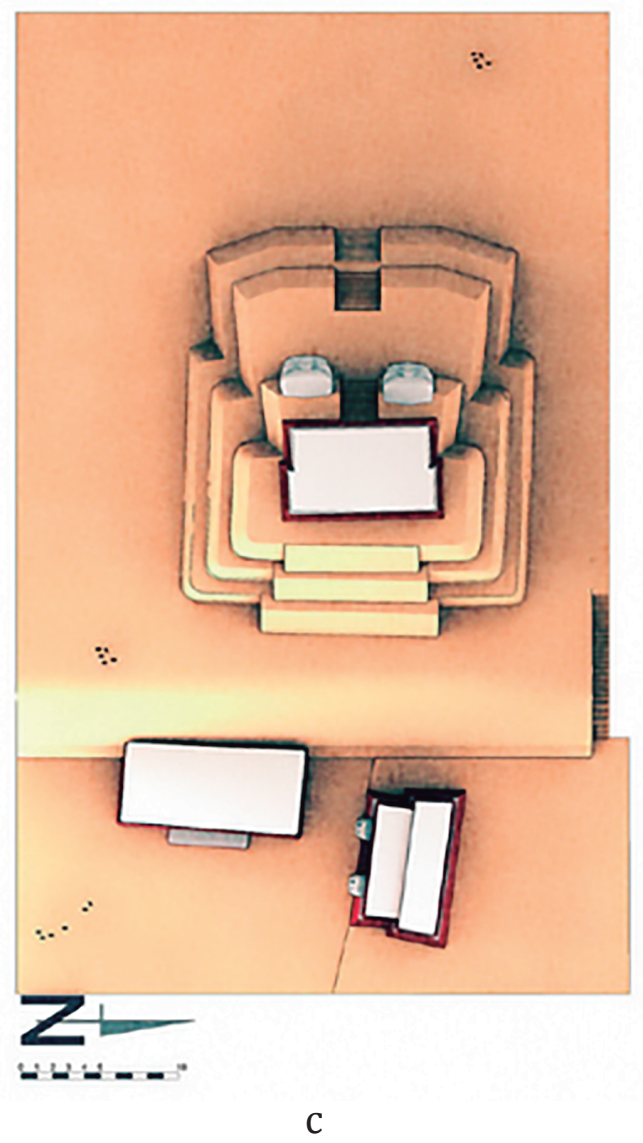

Figuras 6a-c. La sexta fase arquitectónica de la Pirámide de las Pinturas de San Bartolo, El Petén, Guatemala (ca. 100 a.C.).

Imágenes digitales en tres dimensiones realizadas por Massimo Stefani.

en la cual deben ser entendidas, contempladas y usadas; es decir, a través de esta configuración concreta, física, se manifiesta su significación en un nivel profundo.

Dicho esto, se puede apreciar la intención de precisar los espacios superior e inferior, mediados por otro en su intersección, y que se expresan en la siguiente relación tripartita: abajo : nivel intermedio : arriba :: Sub-1A y Sub1B : Yaxché : Ixim. Al hablar de lo horizontal y lo vertical, y del movimiento ascendente (y descendente), ${ }^{19}$ inmediatamente se imponen algunas ideas relacionadas con la

${ }^{19}$ Según Paul Westheim "[...] el contraste entre la tendencia horizontal y el movimiento ascendente del cuerpo piramidal da origen a una tensión que se traduce en intensidad expresiva [...]" (1972: 124). 
cosmovisión de los antiguos mayas: organización espacial del universo (destacando aquí la estructura en tres niveles en sentido vertical); la trayectoria aparente que el sol hace en un día; el movimiento que los hombres — los usuarios de esos espacios-, al parecer, debieron recorrer al utilizarlos.

Parece factible pensar que las personas que acudían a esos lugares partían de la plaza conformada por dos edificios, Sub-1A y 1B, y posteriormente subían por la escalera colocada en la esquina noreste de la plataforma Yaxché, para terminar una actividad ritual en el templo Ixim; es decir, el ritual completo tenía sentido siempre y cuando se respetara esta secuencia específica.

Hay que notar, además, que la relación de estos tres momentos — los cuales se refieren a la secuencia de los pasos necesarios (entendidos como recorrido) para cumplir debidademente con los requisitos de un rito- se expresa a través de la disposición de los edificios de la antepenúltima fase arquitectónica de la Pirámide de las Pinturas de San Bartolo: la plaza baja de las Sub-1A y 1B la entiendo como nivel infraterrestre - inframundo-, luego se sube por la escalera de Yaxché como nivel intermedio - tierra-, y se llega a lo alto —al cielodonde está el templo Ixim. A saber, esa configuración espacial me hace pensar en una posible jerarquización en la utilización de los edificios, en sentido de una secuencialización, es decir, obedece a un orden espacio-temporal dentro de una actividad ritual, que comprende (por lo menos) tres momentos diferentes. A saber, se trata de procesiones que, por lo visto, siguen un orden preciso (en el entorno construido, en este caso concreto) y se acompañan con las recitaciones de leyendas asociadas con un circuito primordial que mentalmente constituye un territorio; las palabras de Gérard Toffin (2003: 680-681) describen esta situación de la siguiente manera:

Esta noción de recorrido, con paradas, que reactiva un circuito original y que construye un territorio, se encuentra en numerosas culturas. [...] La recitación periódica de las leyendas de ocupación [...] constituye un elemento importante de la vida socio-religiosa. [...] Traen a la memoria el itinerario que siguieron los antepasados cuando fundaron las aldeas, los episodios relacionados, el orden de la creación de los asentamientos humanos, toda una memoria clánica de la que aún depende la organización social actual. La recitación [...] opera como un retorno a las fuentes, un retorno a la época de las fundaciones.

Por otro lado, es factible pensar que esta fase constructiva no favorece una sola orientación, sino dos: hacia el oeste (Ixim) y el este (Sub-1A). De esta forma, no se otorga una mayor importancia a ninguna de esas dos plazas, sino se destaca su valor de igualdad y la intención de ser utilizadas de forma conjunta en un ritual complejo. Es probable que esas dos orientaciones estén en relación con la rotación de la tierra alrededor del sol, percibida como el aparente trayecto de éste alrededor de la tierra. El hecho de que la plaza formada por la Sub-1A y la Sub-1B de al oriente y aquella marcada por Ixim hacia el poniente indica, efectiva- 
mente, esa trayectoria solar, al tomar en consideración que este astro se levanta en el este y se pone en el oeste, ${ }^{20}$ lo que tiene paralelo con la creencia maya de que el sol sale del inframundo y va hacia el cielo, lo cual está en consonancia con lo dicho antes acerca de la disposición de esos edificios que señala los tres niveles del universo (el inframundo, la superficie terrestre y el cielo).

De este modo, la plaza conformada por las subestructuras $1 \mathrm{~A}$ y $1 \mathrm{~B}$ es el inframundo del que sale el sol en el este -la orientación de esta plaza-, se alza (pasando por el nivel terrestre) y va subiendo hacia el cielo, hacia el oeste - hacia donde está volteada esta plaza_, para volver a meterse en el mundo subterráneo. Así, los edificios están colocados para indicar una idea; son espacios conceptuales, es decir, quedan almacenados en la memoria y se fundamentan en las creencias y la mitología particulares, en este caso de los antiguos mayas, y pueden tomar formas con diferente grado de figuratividad.

Esta configuración específica del complejo estudiado de San Bartolo sugiere la diferenciación en cuanto a sus posibles usos, significaciones y funciones. En términos greimasianos (Greimas, 1983), la significación es de naturaleza relacional, lo que quiere decir que el sentido se produce al tomar en consideración las relaciones de las partes que configuran una totalidad. Concretamente, se examinan las articulaciones entre dos plazas que forman a la sexta fase arquitectónica del grupo las Pinturas, así como las articulaciones entre los que se presenta en el espacio exterior y en el interior, con sus especificidades arquitectónicas, escultóricas y pictóricas.

Así, cuando se crea un espacio dedicado a rendir culto, a cantar, a danzar y a otras actividades que lo acompañan (es decir, un espacio destinado al uso ritual), es necesario pensarlo como una totalidad, configurada por el entorno, su exterior e interior, y con las demás características que lo conforman. Se trata de los espacios creados intencionalmente de una manera determinada —intelectual y sensiblemente- para significar algo. Esta misma configuración visual revela qué es y para qué es. En las culturas dominadas por las creencias religiosas, como la maya antigua, son los espacios materiales, reales, manifestados e imbuidos de un componente espiritual; por ello, abundan los signos visuales que los designan, como, por ejemplo, los signos del aliento (vital) y del viento, ambos expresados en forma de volutas - fenómenos invisibles hechos visibles - tanto en el exterior como en el interior. ${ }^{21}$

Cada una de las estructuras de la antepenúltima fase arquitectónica es una totalidad y todos los elementos que las componen adquieren su verdadera signifi-

${ }^{20}$ Sería interesante contar con las mediciones arqueoastronómicas de este complejo arquitectónico.

21 Por lo general se presentan en pares, bifurcándose en direcciones opuestas. En el grupo las Pinturas de San Bartolo en el exterior de las estructuras se pintaron en colores rojo y rosa alrededor de las figuras antropomorfas, mientras que en el interior en rojo, negro y gris y se relacionan con diversas figuras. Cuando circundan a las figuras antropomorfas, pueden referirse a su vitalidad o presencia, aunque estén en otro espacio-tiempo. También pueden indicar el fuego. 
cación cuando se consideran como un conjunto. Por ser contemporáneas, fueron edificadas con la finalidad de usarse al mismo tiempo. Para subrayar esta idea, la Sub-1A está conectada físicamente con Yaxché. Además, estas dos plazas están unidas mediante una escalera, por lo que se facilita el tránsito entre ellas; lo mismo se observa en el caso de la pirámide Hunahpú y la cancha del juego de pelota.

David Freidel y Charles Suhler (1999) en su estudio "The Path of Life" sobre el análisis funcional de la arquitectura maya antigua, ${ }^{22}$ analizan las implicaciones del diseño físico de edificios condicionado por su planta o por medio de otros elementos plástico-constructivos, los mismos que se pueden pensar en términos del plano del recorrido o camino; en San Bartolo la configuración de un grupo arquitectónico entero expresa, considero, este concepto. Estos autores indican que ese camino pudo haberse referido al viaje desde la muerte hacia la vida, mientras que también muchas otras diferentes actividades se podían efectuar ahí. Piensan también que el diseño que indica un camino fue principalmente incorporado a los edificios públicos para celebrar el ascenso de los gobernantes.

La idea principal es que los edificios mayas no fueron diseñados únicamente como monumentos estáticos que demuestran el poder de sus patronos, sino como lugares en los cuales se llevan a cabo los eventos simbólicos que conectan a los gobernantes tanto con sus seguidores humanos como con sus patronos míticos, con lo que se reforzaba el poder transcendental de esos lugares. Así, a través de esas edificaciones hechas en el mismo lugar, unas encima de las otras, se conectan las personas existentes con sus ancestros, permitiendo la unión de varias temporalidades a la vez.

Freidel y Suhler argumentan que se trata de una variedad de diseños formales que caben dentro de la categoría de "lugares de caminos"; por su manifestación física se puede aseverar que es un camino en sentido vertical, el que lleva desde el mundo infraterrestre, o del interior del santuario, hacia encima de la tierra, al área del techo e, idealmente, a un andamio en el aire. Estos autores opinan que todas las estructuras se podrían llamar witz, "montaña" (que sobrentiende el complejo montaña-cueva), independientemente de que los edificios públicos al mismo tiempo desempeñaban muchas funciones.

\section{Características principales de las estructuras}

Entre las características que poseen los tres edificios de la sexta fase arquitectónica de las Pinturas hay que destacar la presencia de la pintura mural tanto en los exteriores como en los interiores (Figuras 7a-d), con excepción de que la pintura del interior de la Sub-1B no se encontró in situ, sino en fragmentos pintados, mientras que en el exterior se preservó una figura y los textos jeroglíficos en las paredes verticales de la fachada principal.

\footnotetext{
${ }^{22}$ El principal objeto de su estudio son las particularidades constructivas de la estructura $6 \mathrm{E}-120$ del sitio Yaxuná, Yucatán.
} 


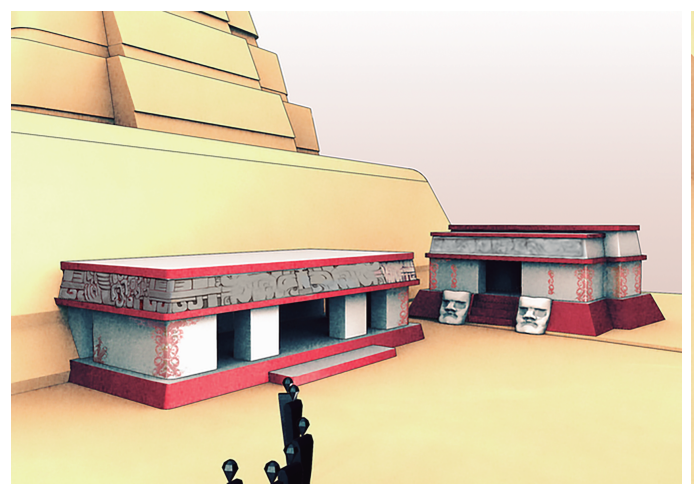

a

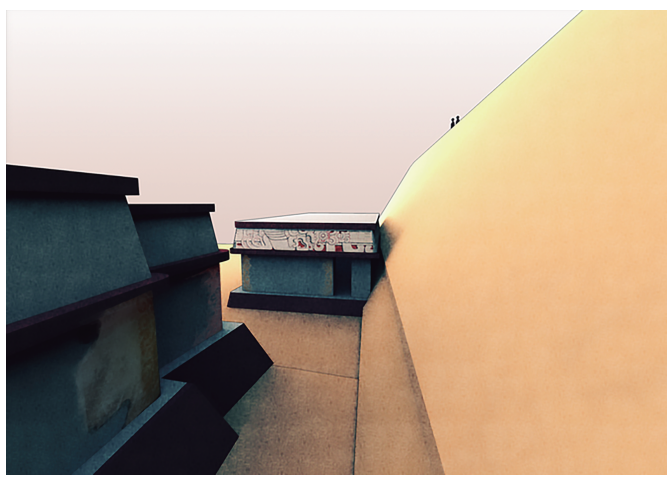

C

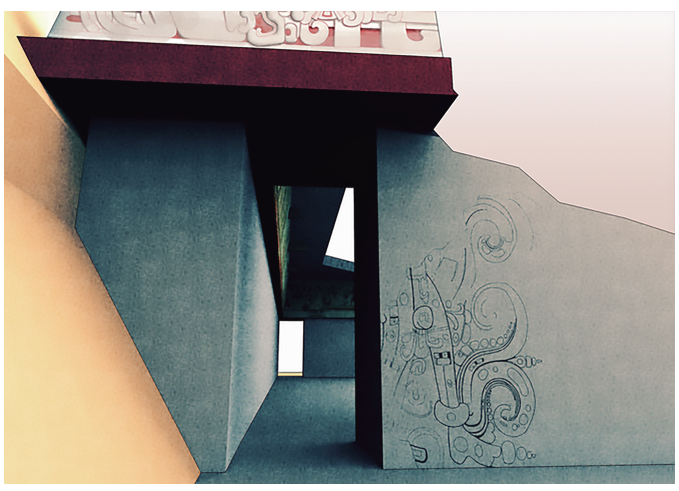

b

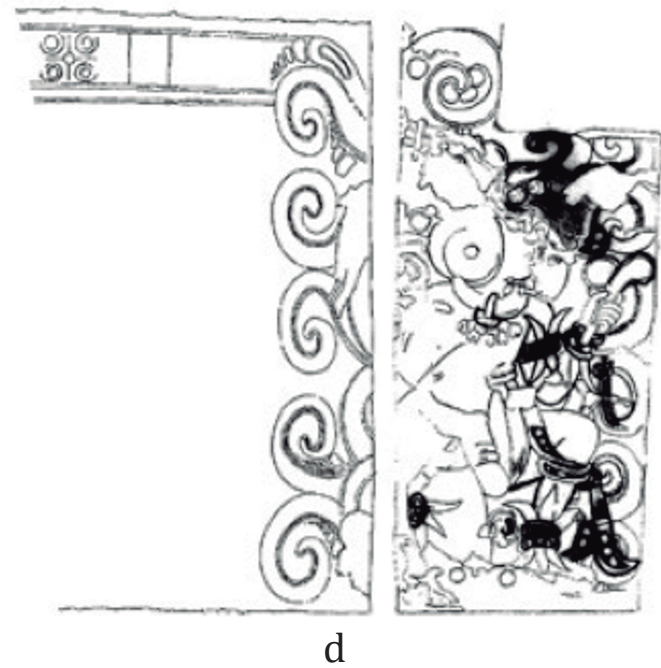

Figuras 7a-d. Diferentes manifestaciones plásticas plasmadas en el exterior de los edificios Sub-1A y Sub-1B; la sexta fase arquitectónica de la Pirámide de las Pinturas de San Bartolo, El Petén, Guatemala (ca. 100 a.C.). a-c. Imágenes digitales en tres dimensiones realizadas por Massimo

Stefani. $d$. Dibujos de la figura antropomorfa entre volutas y de la banda "astral" en el registro superior, pintadas en el exterior de la Sub-1B. Dibujado por Dragisa Busic (izquierda) y Sarah Galais (derecha).

Ixim, por su parte, actualmente cuenta con pequeñas porciones de los murales pintados en su lugar original; sin embargo, la mayor parte proviene de los pedazos del relleno. En la actualidad el discurso pictórico más largo se encuentra en el interior de la Sub-1A y en su exterior se puede apreciar una buena parte de la cornisa, con relieve modelado en estuco y pintado, así como con algunas figuras pintadas en las paredes verticales. Adicionalmente, los elementos que se encuentran en el exterior de la Sub-1B e Ixim, y no en la Sub-1A, son los mascarones que flanquean las escalinatas. 
La característica arquitectónica común a los tres edificios son los techos planos; se trata de un rasgo importante, bastante ingenioso y nada fácil de construir; con la finalidad de dar la estabilidad a esos techos, se colocaron vigas de madera en el interior de los edificios. Varios investigadores consideran que su función principal fue la de favorecer la observación de las pinturas en el interior y de no interrumpir la vista.

Los muros este y sur de la Sub-1A fueron cortados hacia sus hiladas basales (Figura 8); queda in situ una pequeña porción del Mural Este en el rincón noreste. Afortunadamente, las paredes de los lados norte y oeste están bien preservadas, en su mayor parte, hasta el nivel del techo. Esta estructura todavía tiene el relleno puesto por los mayas antiguos, ya que la mayor parte del espacio interior se necesitó excavar (en forma de túneles) para juntar fragmentos de estuco pintado, pertenecientes a los murales y a la cornisa.

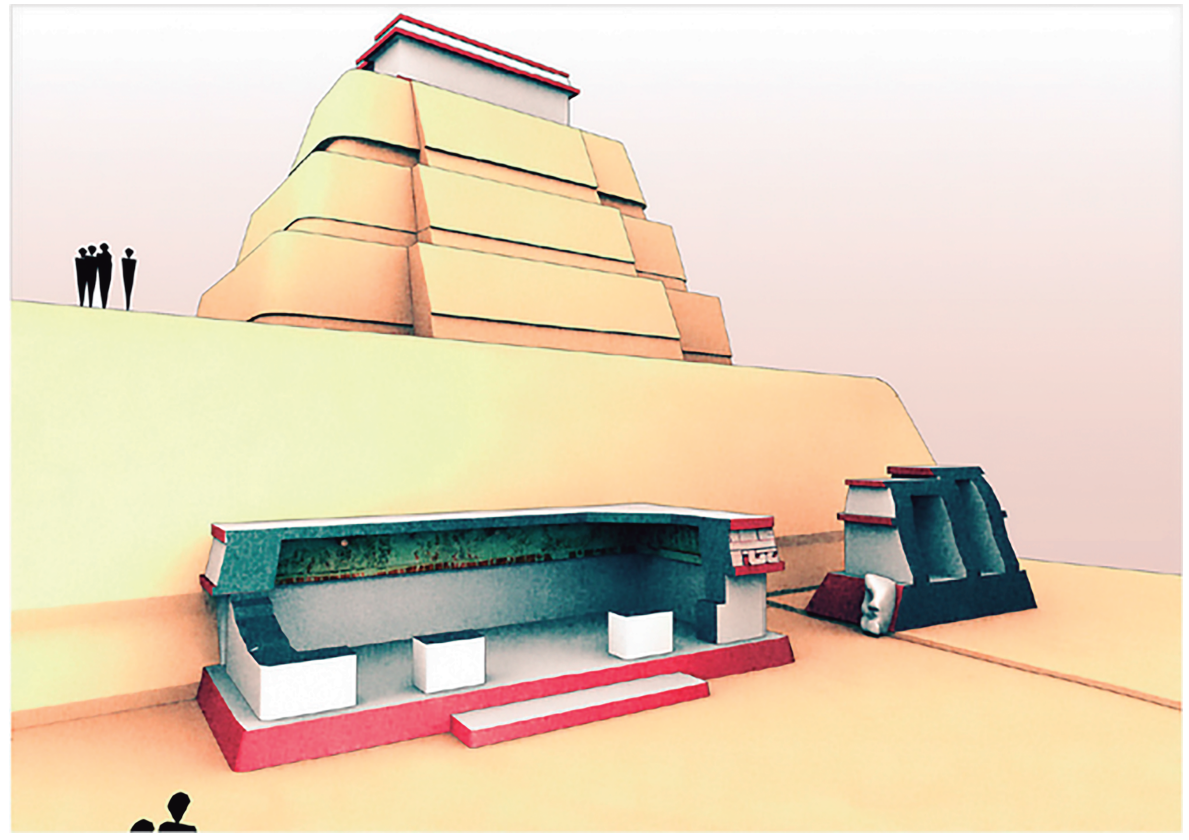

Figura 8. La sexta fase arquitectónica de la Pirámide de las Pinturas de San Bartolo,

El Petén, Guatemala (ca. 100 a.C.) tras el desmantelamiento intencional de los edificios. Imagen digital en tres dimensiones realizada por Massimo Stefani.

Sus dimensiones exteriores son ca. $4.7 \mathrm{~m}$ por $10.7 \mathrm{~m}$; su planta presenta forma rectangular y está construida encima de una plataforma pintada de color rojo en forma de delantal, que tiene ca. $0.6 \mathrm{~m}$ de alto. Su fachada frontal está orientada al este y posee tres vanos anchos, además de dos laterales en cada una de las esquinas (suroeste y sureste), terminando en la base de la plataforma Yaxché. 
Los cinco miden ca. $1.4 \mathrm{~m}$, pero su ancho es distinto; el vano central de la fachada principal tiene la extensión de $c a .2 .6 \mathrm{~m}$ (relacionado con un peldaño), dos que están junto a él son de $c a .1 .3 \mathrm{~m}$, y los laterales son todavía más angostos.

En la Sub-1A las paredes exteriores verticales se elevan $c a .1 .5 \mathrm{~m}$ desde la plataforma, lugar donde empieza la cornisa un poco inclinada, con relieve en estuco modelado y pintado, aproximadamente de un metro de altura (Figuras 7a-c); fue casi totalmente removida de su lugar original y colocada dentro del relleno que cubrió al edificio para dar el paso a una nueva versión, menos la parte del lado norte que se encuentra en su lugar original. Se observa que esta cornisa engloba al edificio de los tres lados y termina en el lugar donde se halla la plataforma Yaxché.

En las paredes verticales del exterior, es decir, entre la cornisa y la plataforma, la Sub-1A cuenta con pinturas policromadas en las esquinas y cerca de los vanos; destacan las volutas en colores rojo y rosa, diseños similares a los encontrados en las estructuras Sub-1B e Ixim de San Bartolo, la Sub 1 de Cival, la estructura 5D-Sub-10-1 a de la Acrópolis Norte de Tikal y la estructura norte de la Plaza B de Wakna, por mencionar algunas. En cuanto a la Sub-1A, aún no se conocen todos los detalles y es necesario esperar a que terminen los trabajos de conservación y restauración. Saturno señaló que las figuras antropomorfas se encuentran en las esquinas del edificio y alrededor de sus cinco vanos; no obstante, no queda claro si en todos esos casos se trata sólo de las volutas o las figuras antropomorfas entre las volutas.

Ver determinadas manifestaciones en su contexto concreto, en el cual se quiebran los planos y la visión de un continuum espacial se interrumpe, donde se exigen las miradas sucesivas —es decir, el movimiento del observador- para captar una imagen en su totalidad, es imperativo para poder entender aquellas plasmadas en la Sub-1A. Contrariamente a eso, actuar como observador estático y, por otro lado, poder (y tener que) caminar en un espacio proyectado e incorporado, suscita otra experiencia e instiga una significación diferente. Los sujetos humanos son quienes utilizan los espacios, por lo que tienen relevancia sus comportamientos programados y se los pone en relación con el uso que ellos hacen del espacio; esta inscripción de los programas narrativos en los espacios segmentados constituye la programación espacial, de orden funcional (Greimas y Courtés, 1982: 153-154).

Siguiendo los argumentos de Christopher Tilley (1994: 16-17), el espacio denominado existencial o vivido está intrínsecamente ligado al espacio perceptual, ya que es construido a través de las experiencias concretas de los individuos socializados en el marco de un grupo. Este tipo de espacio está en proceso de producción y reproducción constante a través de movimientos y actividades de los miembros de un grupo. Es espacio para una experiencia móvil y no pasiva. Es experimentado y creado a través de las experiencias de la vida, es sagrado, simbólico y mítico, repleto de significados sociales que envuelve a los edificios, objetos y particularidades de la topografía local, proporcionando puntos de referencia y 
rejillas de la orientación emocional para el apego y la participación humanos. Lugares en espacio existencial son focos de la producción de significado, intención y propósito de significación societal. Los límites o barreras son de mayor significación para la estructuración del espacio existencial tanto entre lugares como entre regiones. A través de los límites se crean diferencias y oposiciones sociales, estableciendo las diferencias sociales y culturales, asimismo la alteridad.

Para el mismo autor, el espacio arquitectónico obtiene el sentido sólo en relación con el espacio pragmático, perceptual y existencial, pero implica la intención deliberada para crear y fijar espacio: crear un interior, un exterior, un camino alrededor de él, un circuito para el movimiento. La arquitectura es la creación deliberada del espacio hecho tangible, visible y sensible. Por eso los edificios juegan el papel fundamental en la creación y la recreación, la producción y la reproducción del espacio existencial y tienen efectos profundos de estructuración en el espacio perceptual.

Tilley concluye que el espacio sólo puede existir como un conjunto de relaciones entre cosas o lugares. En este sentido, no hay espacio que no sea relacional. Espacio se crea a través de las relaciones sociales, asimismo mediante los objetos naturales y culturales. Es más una producción, una realización que una realidad autónoma en la cual las cosas o las personas "se localizan" o "se encuentran". Puesto que son constituidas por cosas y lugares, las relaciones espaciales afectan al modo en que se relacionan; es decir, se trata de una dialéctica socio-espacial: espacio es, a la vez, constituido y constituyente.

Si espacio es medio para la acción, recurso en el cual los actores se apoyan para su actividad y lo usan para sus necesidades, entonces es imbuido de valores, es político y de ninguna manera es neutral. Los espacios de las sociedades no occidentales precapitalistas se caracterizan por tener densidades diferentes, por el componente sensorial, por ser consagrados, ritualizados, antropomórficos y cosmológicos, donde la arquitectura es personificación, es de mito y cosmología, por ser donde el paisaje es forma ritual sedimentada y el tiempo se constituye de ritmos de acción social en espacio-tiempo (Tilley, 1994: 20-21).

Volviendo al espacio arquitectónico del grupo las Pinturas de San Bartolo propiamente: por estar adosados a la arquitecura, los volúmenes de los edificios pueden imponer la relevancia de un espacio tridimensional porque las manifestaciones plásticas, así configuradas, demandan ser aprehendidas en más de un ángulo de observación. Así, el contexto es espacio inculcado con la conciencia histórica. Por lo tanto, más que ser vistas tal y como lo entendemos hoy en día (en un sistema óptico-visual), estas imágenes fueron hechas para significar determinados conceptos - relacionados con los temas del orden político y cósmico-, rebasando la mera dimensión física del objeto y convirtiéndose en expresiones visuales de esos conceptos (en forma de diferentes monumentos, pinturas murales, a través de la arquitectura u otros objetos), que continuamente se reactivaban por medio de acciones rituales. 
De los elementos pictóricos del exterior de los tres edificios, los que mejor se preservaron tras el desmantelamiento intencional son los de la Sub-1B en la esquina remetida del lado oeste del edificio (Figuras 7c-d); se trata de una figura antropomorfa masculina entre las volutas (hincada, con un pie sobre el piso y la otra pierna flexionada en la rodilla, sujeta un hacha y tiene un peinado particular), una banda colocada inmediatamente debajo de la cornisa y una columna de jeroglíficos. La particularidad de esta pintura es que las volutas rebasan una esquina del edificio y pasan al muro contiguo, puesto que se trata de la esquina remetida.

Las Pinturas Sub-1B es un edificio cuya planta tiene la forma de $T$ y se localiza a $c a .1 .8 \mathrm{~m}$ al este de la plataforma Yaxché, con orientación hacia el sur y el eje longitudinal hacia el este-oeste. Ese tipo de estructuras se caracterizan por poseer dos crujías, una frontal y otra posterior, de las cuales la frontal es menos larga que la posterior; además, las cámaras posteriores se encuentran en un nivel más elevado que las de la galería anterior y las crujías son más angostas. El mismo diseño — la forma de T- lo tiene el edificio Ixim, sólo que sus dos crujías están divididas cada una en tres cámaras, siendo seis en total. Este diseño de la planta es recurrente en el período Preclásico y se halla en diferentes sitios.

La Sub-1B está elevada $c a .1 .1 \mathrm{~m}$ sobre una plataforma inclinada y pintada de rojo, articulada con una moldura baja; esta estructura tiene una altura de $c a .1 .6$ $\mathrm{m}$ y se encuentra preservada al nivel de la primera hilada de la cornisa. El edificio fue cortado a lo largo del eje norte-sur por la construcción de la siguiente fase, dejando sólo una pequeña porción del programa total, mencionado anteriormente (aproximadamente una tercera parte).

La estructura Ixim fue erigida sobre la plataforma Yaxché y sobre un basamento piramidal de tres cuerpos con esquinas remetidas, las cuales presentan un acabado de estuco de color natural; el basamento contaba con los mascarones que flanqueaban la escalera. La fachada frontal de Ixim (del lado oeste) fue muy dañada al momento de la construcción de la siguiente etapa. De los pocos rasgos definidos sobresale un talud de $c a .4 \mathrm{~m}$ de largo por $3.2 \mathrm{~m}$ de alto al centro de la pirámide, en donde está una escalinata remetida y flanqueada por dos mascarones; lamentablemente, éstos se encuentran en un mal estado de preservación por haber sido mutilados y despojados del estuco que los revestía.

Ixim es una estructura con la planta en forma de T, igual que la Sub-1B; la cámara principal de la crujía frontal da acceso a esa estructura; tiene aproximadamente $2.5 \mathrm{~m}$ de altura, $3.7 \mathrm{~m}$ de largo y $5.8 \mathrm{~m}$ de ancho. Esa cámara contaba con un programa pictórico que ocupaba toda la superficie de las paredes, es decir, estuvo pintada del piso al techo. La paleta cromática utilizada en el interior de este edificio cuenta con mayor número de colores ${ }^{23}$ en comparación con la Sub1A. En las cámaras posteriores se encontraron muchas áreas quemadas en el piso y el estuco de las paredes tenía marcas negras en algunas partes, algo que no se observa en las cámaras anteriores.

${ }^{23}$ Cuenta con diversos colores, entre ellos el verde, que no están presentes en la Sub-1A. 
Ahora bien, es menester destacar la importancia del diseño de la planta en forma de $\mathrm{T}$ en los términos que le dio Julia Guernsey (2010), quien considera que se trata de un trifolio, entendido como cuadrifolio parcial. ${ }^{24}$ Esta figura se manifiesta en muchos medios desde los tiempos más tempranos en varios lugares de Mesoamérica. En cuanto a las manifestaciones volumétricas, como arquitectura y escultura, esta autora argumenta que existen numerosos intercambios y reciprocidad en la configuración, contexto y orientación (horizontal o vertical) por su peculiar plasticidad. Desde el período Preclásico Medio se erigieron las estructuras con las esquinas remetidas, que les dieron la forma cuadrifoliar. Por lo menos desde el Preclásico Tardío en el área maya, los contornos configurados como cuadrifolios caracterizaban las plataformas que soportaban los edificios (Figura 9). Parece que también la forma completa de las pirámides radiales —vistas desde arriba - se considera un cuadrilóbulo horizontal (Figuras 3a, 10a-b).

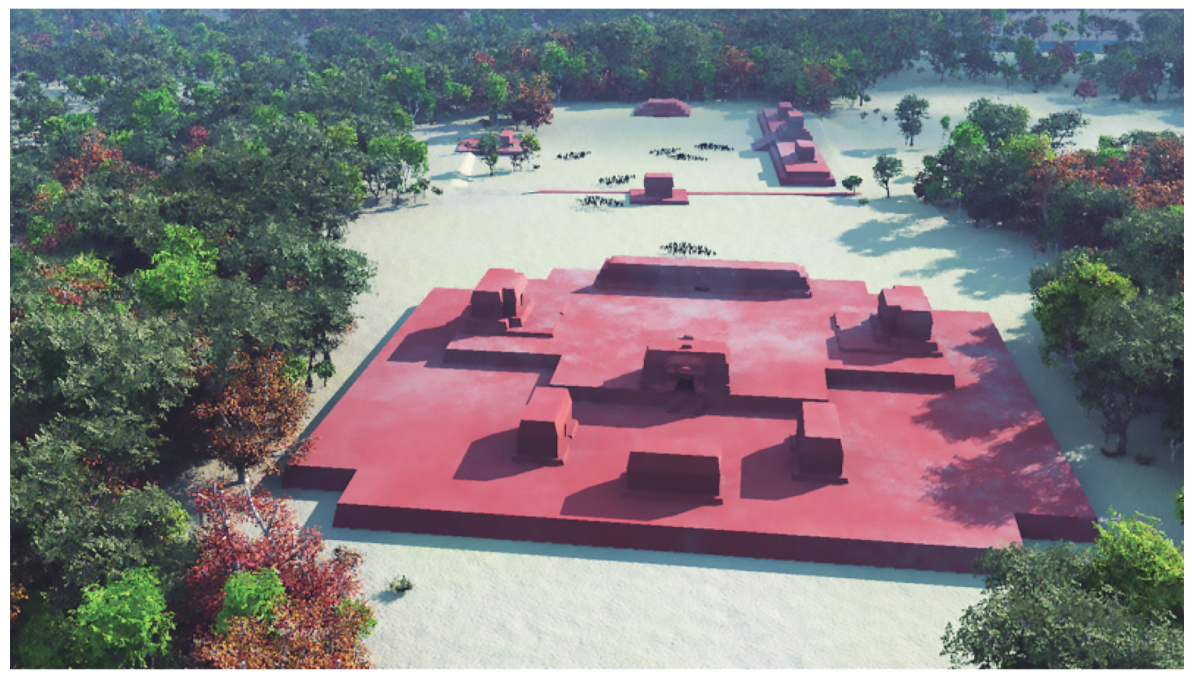

Figura 9. Reconstrucción hipotética de la tercera fase arquitectónica de la Estructura II de Calakmul, Campeche, México (Preclásico Tardío). Nótese la forma de las plataformas. Imagen digital en tres dimensiones realizada por Massimo Stefani.

Guernsey sugiere que las plataformas que tienen esa forma marcan la intersección entre el inframundo y el mundo terrenal, siendo este último sugerido a manera de pirámides, consideradas como montañas hechas por la mano humana. Su aspecto físico remite a un complejo de ideas relacionadas con la comunicación con lo sobrenatural, el tiempo, los umbrales, los reinos acuáticos, así como con las celebraciones calendáricas, dinastías gobernantes, cosmología y el universo cuatripartita.

\footnotetext{
${ }^{24}$ Cuando la parte se identifica con el todo (sinécdoque).
} 


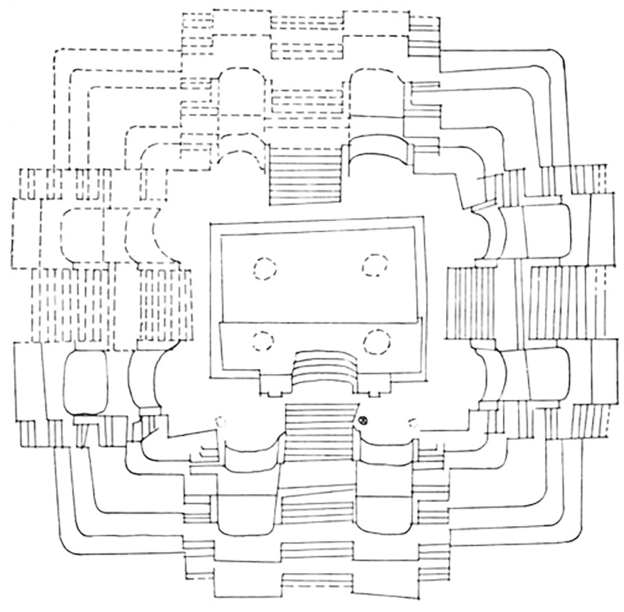

a

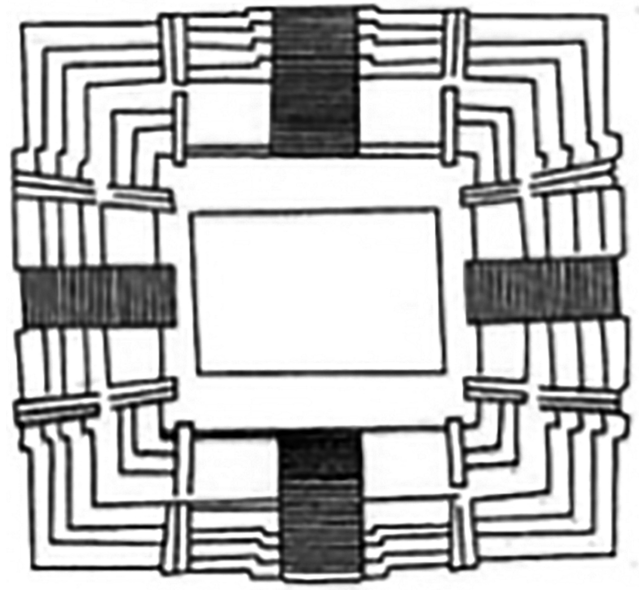

b

Figuras 10a y b. a) Planta de la Estructura E-VII-Sub de Uaxactún, El Petén, Guatemala (Preclásico Tardío) < http://archiveofaffinities.tumblr.com/post/26817400814/e-vii-sub-pyramid-planuaxactun-guatemala $>$. b) Planta de la Estructura 5C-54-4 de Tikal, El Petén, Guatemala (Preclásico Tardío). Julia Guernsey (2010: 87, figura 13). Fuente original: Juan Pedro Laporte (1999).

Indica que son metáforas creadas con la figura de cuadrifolio desde el Preclásico Medio, adoptadas por la elite para dar forma física, arquitectónica, a sus ámbitos o escenarios rituales. Es la forma que prácticamente fue utilizada en todos los medios para designar un portal "supernatural" para los gobernantes, que marcaba lugares específicos dentro del entorno construido. Al mismo tiempo, la cancha del juego de pelota, entendida también como portal que lleva al interior de la tierra, tiene la forma de I o de $\mathrm{T}$-que se parecen a dos cuadrifolios parciales y recuerdan a un cuadrifoliar completo si mentalmente se conectaran como en espejo-. ${ }^{25}$ Además, muchas veces se trata de los lugares hundidos.

Guernsey concluye que el cuadrifoliar fue concebido como el mundo infraterrestre —el de las cuevas húmedas y los umbrales acuáticos-, que los gobernantes evocaban en momentos históricos específicos para justificar la declaración de su autoridad política; simbolizaba el espacio mítico manifestado a través de la arquitectura en un entorno construido.

En relación con esta aseveración, hay que contemplar el diseño de las plantas de los tres edificios de San Bartolo y sus otros rasgos (Figura 6c). En dos casos - Sub-1B e Ixim - se trata de plantas diseñadas en forma de T, las cuales se refieren, en efecto, a los cuadrilóbulos parciales (o trilóbulos). Por otro lado, la forma de la planta de la Sub-1A es rectangular, pero posee cinco vanos, de los

25 Por ejemplo, los marcadores del juego de pelota de Copán tienen también la forma cuadrifoliar. 
cuales uno es la entrada/salida, mientras que la función principal de los otros cuatro, considero, es la de indicar, precisamente, el cuadrifoliar. ${ }^{26}$ También hay que recordar que en la tercera fase constructiva de la Pirámide de las Pinturas hay una pirámide radial y una cancha de juego de pelota, con lo que se subraya la importancia de la figura de tri o cuadrifoliar y su relación con la concepción maya del inframundo, la misma que arquitectónicamente se repite en las fases posteriores en diferente tipo de configuraciones. Así mismo, el juego de pelota está adosado a la pirámide Hunahpú, tal como lo es Sub-1A a Yaxché.

Por consiguiente, se trata de las formas distintas que se refieren a la misma idea general, esto es, al hecho de construir las cuevas artificiales —claro está, siempre dentro de una montaña-, e insertadas en un mismo contexto. Esas cuevas se presentan, en otros lugares, como cabezas con las bocas o fauces abiertas por las que se puede ingresar a su interior (son cuerpos o partes de los cuerpos de las figuras polimorfas por lo general). David Stuart (1987) identificó diferentes estructuras mayas antiguas como montañas personificadas, es decir, como witz, lugares sobrenaturales asociados a la comunicación con el nivel celeste y la morada de los ancestros. Adicionalmente, estas figuras polimorfas se refieren al punto de contacto entre el inframundo y el cielo, y se vinculan asimismo con las montañas, las cuevas, el agua y la fertilidad.

Los conceptos parecidos aparecen entre diferentes culturas oaxaqueñas prehispánicas o del tiempo del contacto con los europeos, y también están presentes entre los mayas actuales del vecino estado de Chiapas, quienes "conciben a su espacio habitable como un ser viviente, igual que a los cuerpos de los hombres que abriga y cuya reproducción permite" (Ségota, 2008: 759).

\section{Espacio interior de la Sub-1A}

El discurso pictórico más largo y mejor preservado de los edificios de la sexta fase arquitectónica de la Pirámide de las Pinturas de San Bartolo hoy en día se encuentra en el interior de la Sub-1A (Figura 8). ${ }^{27}$ Tres murales se preservaron in situ en el interior de la dicha estructura: el Mural Oeste (ca. $9.5 \mathrm{~m}$ de largo), ubicado enfrente del observador cuando éste ingresa a la Sub-1A; volteando hacia la derecha, se posiciona ante el Mural Norte ( $c a .4 .5 \mathrm{~m}$ de largo); girando todavía más a su derecha, encara al Mural Este, del cual solamente queda una pequeña porción. ${ }^{28}$ En este edificio las paredes están divididas en dos partes: una mayor que se eleva verticalmente desde el piso hasta la altura de $c a .1 .2 \mathrm{~m}$; en ese lugar

\footnotetext{
${ }^{26}$ Además de permitir una buena iluminación y ventilación del espacio interior.

${ }^{27}$ Como el objetivo principal de este ensayo es tratar de entender la significación del arte y del entorno construido de los mayas del Preclásico, concretamente del grupo las Pinturas de San Bartolo, Guatemala, desde la perspectiva de la construcción de espacios arquitectónicos y pictóricos, la interpretación iconográfica queda en segundo plano, por lo que no se muestran imágenes de los murales en detalle. La persona interesada debe acudir a otros estudios relevantes que se mencionan a continuación.

${ }^{28}$ Para apreciar los tres murales en detalle, véase Savkic, 2012: Lám. 12.
} 
está una parte saliente que irrumpe la verticalidad de los muros; a partir de ahí inicia el friso que mide ca. $80 \mathrm{~cm}$ hasta el techo.

La porción inferior de las paredes, en gran parte, no fue pintada; cuenta con una banda policromada, que de manera horizontal recorre las cuatro paredes y está colocada justo debajo de la saliente. El friso saliente permitió la existencia de un espacio que fue pintado de rojo; este color rebasa el límite de esa pequeña superficie, pasando al espacio superior, por lo que deja visible una línea roja lisa y relativamente delgada, logrando un tipo especial de tratamiento de los bordes. Al mismo tiempo, en el Mural Oeste se preserva una pequeña parte de la banda del lado superior, que sufrió daños severos por estar cerca del techo. Puesto que ambas comparten varios rasgos formales, es razonable suponer que la banda superior también recorría los cuatro muros.

En esta gran superficie pictórica (de ca. $28 \mathrm{~m}$ de largo, tamaño previo al momento del desmantelamiento) preparada debidamente - recubierta con cal y pulida-, primero se pintaron in secco las bandas en sentido horizontal de los lados inferior y superior, para delimitarla y significarla, entre las cuales luego se perfilaron múltiples figuras y objetos; fueron plasmados sobre un fondo usualmente llamado neutro, el mismo que es harmonioso, obvio y estable, de un solo color —el del encalado- uniendo así el plano completo de la pintura; es decir, denota la unidad estructural de la superficie. Además, la percepción de una unidad se subraya con el hecho de que en esta superficie no se pintaron líneas divisorias en sentido vertical entre las escenas. En el rincón noroeste, el cabello de una de las figuras —el de un "bebé" - pasa del Mural Norte al Oeste, "negando" de cierta manera esa división arquitectónica. Otra función de este espacio vacío generosamente visible — a pesar de contener una multitud de las figuras pintadas-, es justo la de destacar las acciones que ellas realizan, transformándolo de esta manera en un recurso sumamente expresivo.

Se podría sostener que en esas pinturas murales se combinan dos lenguajes pictóricos que se complementan: uno esquematizado (el de las bandas) y otro figurativo (el de las escenas plasmadas entre ellas). Esas dos maneras de pintar condicionan un espacio arquitectónico a sus necesidades: éste divide las pinturas, pero por medio de los recursos plásticos se unen (el color rojo que rebasa este borde lo intercede). Dicho en otras palabras, la configuración del espacio desarrolla e impulsa la significación.

La banda inferior está articulada por varios segmentos: en sentido horizontal hay una franja con elementos constantes, la cual se presenta con la repetición rítmica de los mismos signos (J, I y J invertida) y colores (amarillo y rojo con una línea delgada negra con los cuadrángulos pintados a distancias irregulares), y otra segmentada por medio de diversas formas y el empleo de los colores más variados. La primera potencia la idea de unificar toda la obra, de significar la totalidad, mientras que la otra (por ser segmentada) alude a la presencia de diferentes unidades de significado o escenas. Al mismo tiempo, en algunos rincones se encuentran los elementos cuadrangulares en cuyo interior se pintaron diferentes signos. 
Se trata de una composición plástico-formal por medio de la que se logra correlacionar las bandas y las escenas que "enmarcan". Lo que enuncia esta particular solución plástica no es únicamente qué deberíamos mirar, sino cómo deberíamos ver los que estamos mirando. La combinación particular de los signos geométricos y el uso de colores que componen la franja con los elementos constantes de la banda se refieren a dos animales esquematizados: jaguar y serpiente; el primero es manifestado como repetición de los elementos J, I y J invertida entendidos como sus colmillos, y el segundo a través del arreglo de dos colores (amarillo y rojo) y una línea negra con cuadrángulos. Esta última combinación de elementos cromáticos es la misma que aparece en la gran serpiente con plumas pintada en forma figurativa en el Mural Norte.

Cabe mencionar que los cuadrángulos en los rincones de la Sub-1A corresponden, según mi apreciación, a las orejeras que usualmente portan las figuras polimorfas que se entienden como "monstruo witz", de cuyas fauces sale el friso, es decir, las imágenes pintadas. ${ }^{29}$ Desde el Preclásico Medio mesoamericano se conocen múltiples manifestaciones plásticas, sobre todo las esculturas, que se refieren a estos polimorfos de cuyas bocas abiertas salen o se encuentran en su interior las figuras antropomorfas.

Es importante notar que este polimorfo que designa a la montaña-cueva personificada en el interior de la Sub-1A se manifestó como pintura esquematizada en forma de la banda, mientras que en en el exterior del edificio a través de determinadas particularidades arquitectónicas (en la cornisa en la que también se combinan rasgos (esquemáticos) de jaguar y serpiente (con plumas) y aves (en forma figurativa) (Figuras 7a y 7c), más el número de vanos, como vimos anteriormente. Al mismo tiempo, en el friso —en los tres murales preservados in situse pintó dos veces como figura cuadrifoliar vista desde la perspectiva de pájaro (en el Mural Este y también en el Mural Oeste), caracterizada adicionalmente como una tortuga, en cuyo interior se encuentran tres deidades; por otro lado, en el Mural Norte se trata de una cabeza pintada de perfil, con ojos, cejas, fauces y colmillos, cuya parte externa está habitada por diversos animales, mientras que en su interior se halla una mujer arrodillada con una ofrenda en sus manos.

Se puede observar que los antiguos mayas repetían ciertos conceptos de importancia para ellos, tanto dentro como fuera de los edificios, y los expresaban de diferente manera. Acorde a esto, la parte saliente de los murales en el interior de la Sub-1A de San Bartolo está literalmente movida hacia delante y empujada al espacio que ocupa el observador. Ésta es una herramienta de la composición que indica la complejidad de la imagen y sugiere varios planos en su construcción; es, también, la forma real en el espacio real.

\footnotetext{
${ }^{29}$ Véase nota 27 (en torno al tema principal del presente trabajo). Para conocer mejor mi propuesta acerca de la posible significación de los cuadrángulos en algunos rincones de la Sub-1A entendidos como orejeras que usualmente portan las figuras polimorfas, véase Savkic, 2012: 144-158, 311 (figura 39), 343-345 (figuras 78. a-c, 79, 80. a-c), 453 (figura 89).
} 
Por último, los temas de los murales los referiré sólo en breve; para una mayor información sobre la interpretación iconográfica de las pinturas plasmadas en el interior de la Sub-1A de San Bartolo, véase Saturno, Taube y Stuart, 2005; Akkeren, 2006 y 2012; Saturno, 2009; Taube et al., 2010, y Savkic, 2012.

Considero que existe un punto de partida "predilecto" de la "lectura" del discurso visual, el mismo que se encuentra en el rincón noreste en el Mural Norte y que sigue en dirección opuesta a las manecillas del reloj, aunque no hay que descartar una "lectura" cruzada. Se trata de una narración y varios eventos que son secuencializados en el tiempo. ${ }^{30}$

En el Mural Norte se plasmaron dos escenas de desigual tamaño. En la escena de mayor largo se pintó una montaña-cueva personificada; de su boca sale una gran serpiente con plumas y sobre su dorso se encuentran ocho individuos. Hay dos escenas menores: una, configurada directamente alrededor de la figura del dios del Maíz, entendida como el ritual de su investidura, en la cual participan tres mujeres y un hombre, todos arrodillados; otra, compuesta por tres personajes, una mujer y dos hombres, que caminan hacia este dios. Tal escena se ha interpretado como la salida de los primeros hombres de la cueva (del inframundo), pero no hay que descartar la posibilidad de otras significaciones.

En la escena contigua se presenta el nacimiento de cuatro hombres del guaje, colocados alrededor de él, y un personaje (en el centro) que podría ser un sacerdote, por la banda que porta en su cabeza. Son los primeros cuatro hombres creados de la masa del maíz, mientras que el guaje o la calabaza es el lugar del origen de los primeros humanos (que también designa el inframundo); a partir de ese momento empezó una nueva era de los cultivadores de maíz. Este evento es presenciado por otro personaje ricamente ataviado.

De aquí se prosigue al Mural Oeste, dividido también en dos escenas principales. El segmento del lado derecho respcto al observador se relaciona con el (árbol del) centro del mundo y el actor principal es el dios del Maíz, que aparece seis veces en diferentes episodios mitológicos que aluden a su nacimiento, muerte y renacimiento (que acontece en el interior de una tortuga-tierra en forma cuadrilobular); estas escenas las confinan otras dos que se vinculan con los ascensos encima de los andamios: uno mítico y otro histórico, recalcado por la presencia del jeroglífico AJAW, "señor, gobernante”. Presenciamos una asociación entre los gobernantes, el maíz, axis mundi, las riquezas y el poder.

El segmento del lado izquierdo de este mural se refiere a la creación de cuatro rumbos, asociados con el dios Pájaro Principal, la cosmología direccional y el sacrificio (la erección de árboles en cuatro esquinas del mundo en cuyas copas posan cuatro aves con las serpientes bicéfalas en sus picos); ante los árboles cuatro cazadores jóvenes ofrecen su propia sangre, animales y plantas (como comida simbólica de las deidades). El cierre de la narración visual completa sería en el rincón noreste del Mural Este.

${ }^{30}$ Algunos eventos podrían ser simultáneos. 


\section{Consideraciones finales}

Es importante atender la forma en la que los vacíos y las masas fueron configurados en las formas que significan, cómo unas simples superficies adquirieron la capacidad de producir lugares que sirvieran como receptáculos para diferentes imágenes y la manera en la que los artistas lograron resolver los problemas planteados por la configuración del lugar, en la dinámica interna de las imágenes y su modo de ponerlos al servicio al programa iconográfico, asimismo cómo un todo así integrado, por enlazar varios elementos, se convirtió en un objeto complejo, el cual a través de su visibilidad perdió el carácter neutro y, por medio de una determinada intervención humana —que implica una visión condicionada por las creencias y la eficacia ritual—, logró que esa apariencia desplegara algo más allá de su propia visibilidad y obtuviera un estatus existencial a través de la activación ritual y la somatización; es decir, cuando se ve metafóricamente lo que no se ve ópticamente (expresado a través de las determinadas características arquitectónicas, escultóricas y pictóricas).

Paul Westheim (1972: 51) había argumentado que una obra (de arte) se consideraba tan real como cualquier otro fenómeno de la realidad provisto con eficacia mágica; su finalidad era transmitir un concepto — en forma plástica- y no una simple representación de escenas o pensamientos. Esas manifestaciones no están hechas para el observador, no lo integran, y su primera importancia no reside en el efecto de la obra, sino en su supuesto de ser-dios. El efecto cambia cuando se precisa del movimiento del observador (en otro nivel de jerarquía) para percibir la totalidad de una configuración visual y de significarla de esa manera. En ese sentido, puesto que los lugares y el movimiento entre ellos son íntimamente relacionados con la formación de biografías personales, los mismos lugares pueden adquirir historia(s), las capas sedimentadas de significados en virtud de las acciones y los eventos que ahí ocurren. Las biografías personales, las identidades sociales y una biografía de lugar están estrechamente conectadas. La memoria y los movimientos previos en un paisaje (construido) son esenciales para entenderlos (Tilley, 1994: 27).

La tercera fase arquitectónica de la Pirámide de las Pinturas de San Bartolo (ca. 300 a.C.) es un Complejo del Tipo E con un rasgo distintivo que es una pequeña cancha del juego de pelota adosada del lado este de la pirámide radial. Lo más probable es que esta plaza fuera de carácter público y que en ella se celebraran rituales cuyos atributos son difíciles de conocer en la actualidad, principalmente porque las posibles funciones de este tipo de complejos se han entendido de diversas maneras. Sin embargo, me parece factible pensar que la actividad preponderante se relacionaba con la conmemoración de los ciclos temporales.

En la sexta fase arquitectónica de la Pirámide de las Pinturas, fechada cerca del año 100 a.C., las ideas relacionadas con la estructura del mundo en tres niveles en sentido vertical (inframundo, superficie terrestre y supramundo) se manifestó

a través de la configuración arquitectónica particular, que implicaba un camino 
singular que los usuarios de esos espacios debieron recorrer para cumplir debidamente con los propósitos de un ritual. Así, se trata de lugares como contextos para la experiencia humana, construidos en movimiento, memoria, encuentros y asociaciones. Además, el diseño de los edificios, condicionado por la forma de la planta y por otros elementos constructivos-plásticos, se manifestó como una imagen-concepto — la montaña-cueva—, que forma parte de la imaginería religiosa de los mayas antiguos, designándolos como espacios conceptuales; aquí se destaca la relación entre el exterior y el interior, entre salir y entrar.

Otra configuración espacial importante se refiere a nivel horizontal, configurado en forma cuatripartita con el eje central como vínculo entre tres espacios-niveles cósmicos de manera vertical. Adicionalmente, la misma congifuración del entorno construido correspondía a la aparente trayectoria del sol alrededor de la tierra, subrayando la importancia de los ciclos como día y noche, nacimiento y muerte, y todos los ritos asociados a la incorporación y desincorporación social en general.

Por último, considero que el arreglo arquitectónico de cada fase de este complejo fue concebido con base en la mitología y el sistema de creencias de los antiguos mayas: por ejemplo, el isomorfismo cuerpo-universo, microcosmos-macrocosmos, re-creación del universo a través de rituales que implican la destrucción intencional y la re-utilización de diversas manifestaciones visuales como ciclos de creación-destrucción. Por lo tanto, la configuración y el diseño de las estructuras específicas implican significado(s) particular(es) y el movimiento intencionado en el espacio (conocido como camino o circuito ritual), particularmente importante para el performance ritual, cuando los actores participan de modo activo en la experiencia espacial, donde el espacio se transforma por medio del cuerpo humano en movimiento.

\section{Agradecimientos}

Este texto fue redactado durante mi estancia posdoctoral como becaria en el Instituto de Investigaciones Antropológicas de la Universidad Nacional Autónoma de México, por lo que extiendo mi más atento agradecimiento al Programa de Becas Posdoctorales de esta universidad. Igualmente, quisiera expresar mi profunda gratitud a Massimo Stefani, arquitecto y experto en modelación tridimensional aplicada a la arqueología precolombina, por elaborar las imágenes digitales en tres dimensiones de varias fases arquitectónicas de la Pirámide de las Pinturas del sitio San Bartolo del Petén guatemalteco. Agradezco también a Felix Kupprat por hacer dos dibujos pertenecientes a la tercera fase arquitectónica de la pirámide mencionada, asimismo a Gerardo Jiménez Delgado, de la Mapoteca del Instituto de Investigaciones Antropológicas de la UNAM, por elaborar el mapa de las Tierras Bajas mayas. 


\section{BIBLIOGRAFÍA}

Beltrán, Boris y Juan Francisco Saravia

2012 "Investigación y consolidación de túneles, Pinturas Sub-6B Hunahpú, sitio arqueológico San Bartolo", Proyecto Arqueológico Regional San Bartolo-Xultún, Informe de resultados de investigaciones, Temporada de campo no. 11, año 2012, pp. 15-30, Patricia Rivera Castillo y William Saturno (eds.). Informe entregado al Instituto de Antropología e Historia de Guatemala. Guatemala.

Flores Esquivel, Atasta

2010 "Los complejos del Tipo ‘E’ y su asociación con acrópolis o arreglos de tipo triádico: Esbozos de un posible patrón urbano y sus posibles significados”, XXIII Simposio de Investigaciones Arqueológicas en Guatemala, 2009, pp. 111122, B. Arroyo, A. Linares y L. Paiz (eds.). Guatemala: Museo Nacional de Arqueología y Etnología.

Greimas, A. J. y J. Courtés

1982 Semiótica. Diccionario razonado de la teoría del lenguaje. Madrid: Gredos (Biblioteca Románica Hispánica).

Greimas, Algirdas Julien

1983 La semiótica del texto: ejercicios prácticos. Análisis de un cuento de Maupassant. Barcelona: Paidós.

Guernsey, Julia

2010 "A Consideration of the Quatrefoil Motif in Preclassic Mesoamerica”, RES: Anthropology and Aesthetics, 57/58: 75-96. DOI: 10.2307/25769973

Freidel, David y Charles Suhler

1999 "The Path of Life: Toward a Functional Analysis of Ancient Maya Architecture", Mesoamerican Architecture as a Cultural Symbol, pp. 250-273, Jeff Karl Kowalski (ed.). New York: Oxford University Press.

Laporte, Juan Pedro

1999 "Preclásico a Clásico en Tikal: proceso de transformación en Mundo Perdido", The Emergence of Lowland Maya Civilization: The Transition from the Preclassic to the Early Classic, Acta Mesoamericana, 38: 17-33.

Rivera Castillo, Patricia

2009 "Recuperación y análisis de materiales arqueológicos. Investigación cerámica temporada 2009", Informe preliminar de la octava temporada de campo 2009, Proyecto Arqueológico Regional San Bartolo, pp. 136-154, Luis Alberto Romero y William Saturno. Guatemala.

Romero, Luis Alberto y William Saturno (eds.)

2009 Informe preliminar de la octava temporada de campo 2009, Proyecto Arqueológico Regional San Bartolo, Guatemala. 
2010 Informe preliminar de la novena temporada de campo 2010, Proyecto Arqueológico Regional San Bartolo, Guatemala.

2011 Informe preliminar de la décima temporada de campo 2011, Proyecto Arqueológico Regional San Bartolo, Guatemala.

Saturno, William A., Karl A. Taube y David Stuart.

2005 "Los murales de San Bartolo, El Petén, Guatemala. Parte 1. El mural del norte", Ancient America, 7.

Saturno, William

2009 "Centering the Kingdom, Centering the King. Maya Creation and Legitimization at San Bartolo", The Art of Urbanism: How Mesoamerican Kingdoms Represented Themselves in Architecture and Imagery, pp. 11-134, William L. Fash y Leonardo López Luján (eds.). Washington, D.C.: Dumbarton Oaks Research Library and Collection.

Saturno, William (ed.)

2009 Proyecto Arqueológico Regional San Bartolo, Informe anual, octava temporada 2009, Informe entregado al Instituto de Antropología e Historia de Guatemala, Guatemala.

Saturno, William A., David Stuart y Boris Beltrán

2006 "Early Maya Writing at San Bartolo, Guatemala", Science, 5765 (311): 12811283, <http://www.sciencemag.org/content/311/5765/1281.full.pdf>

DOI: $10.1126 /$ science. 1121745 .

Savkic, Sanja

2012 "Valores plástico-formales del arte maya del Preclásico tardío a partir de las configuraciones visuales de San Bartolo, Petén, Guatemala”, tesis de Doctorado en Historia del Arte. México: Universidad Nacional Autónoma de México, Facultad de Filosofía y Letras, Instituto de Investigaciones Estéticas.

Ségota, Dúrdica

2008 "El cuerpo de la noche. La disposición de los relieves en el espacio de la Tumba 5 de Suchilquitongo", La pintura mural prehispánica en México. Oaxaca, volumen III, pp. 741-761, Beatriz de la Fuente y Leticia Staines Cicero (coords.). México: Universidad Nacional Autónoma de México, Instituto de Investigaciones Estéticas.

Stuart, David

1987 Ten Phonetic Syllables. Washington: Center for Maya Research.

Taube, Karl A., David Stuart, William Saturno y Heather Hurst

2010 "The Murals of San Bartolo, El Petén, Guatemala. Part 2: The West Wall", Ancient America, 10.

Tilley, Christopher

1994 Phenomenology of Landscape, Paths, and Monuments. Providence, R.I.: Berg. 
Toffin, Gérard

2003 "Modelos arquitectónicos y orden espacial. Observaciones sobre los espacios mayas y la antropología del espacio. Comentario final”, Espacios mayas: representaciones, usos, creencias, pp. 673-685, Alain Breton, Aurore Monod Becquelin y Mario Humberto Ruz (eds.). México: Universidad Nacional Autónoma de México, Instituto de Investigaciones Filológicas, Centro de Estudios Mayas y Centro Francés de Estudios Méxicanos y Centroamericanos.

Urquizú, Mónica y Heather Hurst

2002 "Las pinturas murales de San Bartolo: una ventana al arte y cosmovisión del hombre prehispánico”, XVI Simposio de Investigaciones Arqueológicas en Guatemala, pp. 325-334, Juan Pedro Laporte et al. (eds.). Guatemala: Museo Nacional de Arqueología y Etnología.

2002 Proyecto Arqueológico San Bartolo, Informe preliminar no. 1, Primera temporada 2002, Informe entregado al Instituto de Antropología e Historia de Guatemala, Guatemala, 2002.

2003 Proyecto Arqueológico San Bartolo, Informe preliminar no. 2, Segunda temporada 2003, Informe entregado al Instituto de Antropología e Historia de Guatemala, Guatemala.

2004 Proyecto Arqueológico San Bartolo, Informe preliminar no. 3, Tercera temporada 2004, Informe entregado al Instituto de Antropología e Historia de Guatemala, Guatemala.

2005 Proyecto Arqueológico San Bartolo, Informe preliminar no. 4, Cuarta temporada 2005, Informe entregado a la Dirección de Patrimonio Cultural y Natural de Guatemala, Guatemala.

2006 Proyecto Arqueológico San Bartolo, Informe preliminar no. 5, Quinta temporada 2006, Informe entregado a la Dirección de Patrimonio Cultural y Natural de Guatemala, Guatemala.

2007 Informe final de la sexta temporada de campo 2007, Proyecto Arqueológico Regional San Bartolo, Guatemala.

2008 Proyecto Arqueológico Regional San Bartolo, Informe anual no. 7, Séptima temporada 2008, Informe entregado al Instituto de Antropología e Historia de Guatemala, Guatemala.

Van Akkeren, Ruud van

2006 “Tzuywa: Place of the Gourd”, Ancient America, 9: 36-73.

2012 Xib'alb'a y el nacimiento del nuevo sol. Una visión posclásica del colapso maya. Guatemala: Piedra Santa Editorial.

Westheim, Paul

1972 Ideas fundamentales del arte prehispánico en México. México: Ediciones Era (Serie Mayor). 